\title{
EL BEATO DEL ARCHIVO HISTÓRICO PROVINCIAL DE ZAMORA
}

\author{
POR
}

\author{
ANA SuÁrEZ GONZÁLEZ \\ Universidad de León
}

\section{RESUMEN}

Los fragmentos 276 y 277 del A.H.P. de Zamora son los testigos de un nuevo códice del Comentario al Apocalipsis atribuido a Beato de Liébana. El Beato al que pertenecen, en escritura visigótica, puede datarse en la primera mitad del siglo $\mathrm{X}$. El presente trabajo recoge el análisis externo e interno de ambas piezas y la edición de su texto, cotejado con el de los restantes ejemplares visigóticos, para situar el volumen al que remiten en el stemma de los beatos conocidos hasta la fecha.

Palabras Clave: Beato de Liébana, Beatos, Escritura visigótica, Fragmentos de manuscritos, Siglo X. Zamora.

\begin{abstract}
Fragments 276 and 277 of the Archivo Histórico Provincial de Zamora provide evidence of a heretofore unknown codex of the Commentary on the Apocalypse by Beatus of Liébana. Written in visigothic script, the Beatus manuscript to which they pertain can be dated to the first half of the tenth century. This study provides an analysis - external and internal- of both fragments, along with an edition of the text, comparing them with the surviving visigothic examples in order to situate the manuscript within the stemma of known Beatus manuscripts.
\end{abstract}

KEY WORDS: Beatus of Liébana, Beatus manuscripts, visigothic script, fragments, $X^{\text {th }}$ century, Zamora. 
No son sólo dos folios de pergamino, son un libro. Y, además, no un libro cualquiera. Se trata de un manuscrito - un unicum - , tiene más de mil años y las cuatro páginas supervivientes recogen parte de los Comentarios al Apocalipsis atribuidos — ¿acertadamente?- a Beato de Liébana ${ }^{1}$.

Probablemente, este último hecho — su contenido- le asegurará lugar privilegiado en futuras aproximaciones de diversa índole al patrimonio bibliográfico medieval hispánico ${ }^{2}$, por delante de otros muchos ejemplares transmisores de obras básicas en la historia de la cultura, formalmente impecables y con mejor salud.

Nos referimos a los fragmentos 276 y 277 del Archivo Histórico Provincial de Zamora ${ }^{3}$, las dos únicas piezas conocidas hasta la fecha de un manuscrito visigótico transmisor del Comentario que, presumiblemente, el citado presbítero lebaniego redactó en el último cuarto del siglo VIII. Son los dos pedazos maltrechos del, recientemente identificado y bautizado, Beato del Archivo Histórico Provincial de Zamora ${ }^{4}$.

Abramos este trabajo con las preguntas que sirvieron para cerrar -0 , mejor dicho, interrumpir - nuestra primera aproximación a los fragmentos: ¿dónde nació el beato del A.H.P zamorano? ¿qué edad tiene? ¿cuál es su lugar en el intrincado stemma de los ejemplares conocidos hasta la fecha?

\section{UN NUEVO BEATO VISIGÓTICO.}

El Beato del A.H.P. de Zamora, volumen atestiguado por tan sólo dos de los no menos de doscientos folios con los que pudo contar originariamente, se

\footnotetext{
1 Mi agradecimiento a D. Florián Ferrero Ferrero y a D. José Andrés Casquero, del A.H.P. de Zamora, al P. Lorenzo Maté, archivero y bibliotecario del monasterio de Silos, al P. Josep Torné Cubells, O. Cist. y a D. José Alfredo Martínez Vega, que realizó las fotografias de los fragmentos.

2 Para conocer el interés suscitado por los Beatos, sirva el exhaustivo repertorio bibliográfico que recoge J. WILliAMS, The illustrated Beatus. A corpus of the illustrations of the Commentary on the Apocalypse, IV, The Eleventh and Twelfth Centuries, London/Turnhout 2002, pp.333-351 (en adelante, The illustrated Beatus IV).

${ }^{3}$ Forman parte en el Archivo Histórico Provincial zamorano de una serie facticia. El fondo se denomina Pergaminos musicales y se compone de 283 piezas signadas correlativamente. En las que nos ocupan, las signaturas figuran en sendos estampillados del A.H.P. dispuestos en el ángulo inferior derecho del recto del 276 y en el ángulo inferior izquierdo del vuelto del 277.

4 Identificado el contenido de las piezas en el verano de 2002, dimos noticia del hallazgo en Dos folios de un Beato en el Archivo Histórico Provincial de Zamora: Anuario del Instituto de Estudios Zamoranos «Florián de Ocampo» 18(2001)287-307, artículo que concebimos como una introducción al presente estudio. Las piezas no pertenecen a ninguno de los códices conocidos hasta la fecha ni proceden del mismo ejemplar que otros fragmentos, por esta razón, creemos que se puede hablar de un Beato del Archivo Histórico Provincial de Zamora.

Textos medievales

Hispania Sacra 55 (2003)
} 
suma a los ¿treinta y cinco? ¿treinta y seis? ¿treinta y siete? beatos identificados -e individualizados - antes del verano de $2002^{5} \mathrm{y}$, específicamente, al corpus de ejemplares visigóticos constituido por los siguientes ${ }^{6}$ :

\section{CUADRO 1}

\begin{tabular}{|l|l|c|c|}
\hline $\begin{array}{c}\text { LUGAR DE CONSERVACIÓN/ } \\
\text { SIGNATURA/ DENOMINACIÓN7 }\end{array}$ & DATACIÓN/ ORIGEN GEOGRÁFICO8 & $\begin{array}{c}\text { SIGLA DE } \\
\text { SANDERS }^{9}\end{array}$ & $\begin{array}{c}\text { SigLA DE } \\
\text { NEUSS }^{10}\end{array}$ \\
\hline $\begin{array}{l}\text { Burgo de Osma, Catedral, } \\
\text { Cod.1 [Beato de Osma }]\end{array}$ & $\begin{array}{l}\text { ¿región burgalesa? ¿norte de } \\
\text { Castilla? ¿Osma? ¿Navarra? ¿El } \\
\text { Bierzo (León)? Probablemente } \\
\text { Sahagún11 }\end{array}$ & O & O \\
\hline
\end{tabular}

5 Cf. A. SuÁrez GonZÁlez, Dos folios, p. 299.

6 Sólo incluimos los beatos enteramente visigóticos. Por ello, no figura en la tabla Roma, Biblioteca Corsiniana (Accademia dei Lincei), 369 (40. E. 6), conocido como Beato Corsini. Realizado en su mayor parte con grafía carolina, los ff. 144-156 presentan escritura visigótica. Datable en el segundo cuarto del siglo XII y relacionado con los manuscritos de Sahagún según B. A. SHAILOR, El Beato de Osma: Estudio paleográfico y codicológico: El Beato de Osma. Estudios, Valencia 1992, p. 55-56.

7 Por lo que se refiere a los beatos conocidos ya en 1985, los datos correspondientes a lugares de conservación y signatura proceden de A. M. MUNDÓ y M. SÁNCHEZ MARIANA, Catalogación: Los Beatos. Europalia 85 España (26 septiembre - 30 noviembre 1985. Chapelle de Nassau, Bibliothèque Royale Albert $\mathrm{I}^{\mathrm{er}}$ ), [Madrid] 1985, pp. 102-127. Para poder recurrir a ellas a lo largo del estudio, y agilizar así el texto, incluimos también las denominaciones de los manuscritos iluminados a partir de J. WILLIAMS, The illustrated Beatus. A corpus of the illustrations of the Commentary on the Apocalypse. Introduction, London 1994, pp. 10-11 (en adelante, The illustrated Beatus I) y J. YARZA LUACES, Beato de Liébana. Manuscritos iluminados, Barcelona 1998, pp. 320-322. A propósito del ejemplar citado en cuarto lugar, cf. T. BURÓN CASTRO, Fragmento de Beato: León y su historia VI, León 2000, pp. 125-139.

8 Para establecer un estado de la cuestión a propósito de estos aspectos, salvo excepciones justificadas, recogeremos únicamente opiniones vertidas en los últimos treinta años, dando prioridad a las hipótesis que gozan actualmente de mayor número de adeptos entre los expertos.

9 Son las siglas atribuidas a los beatos por H. A. SANDERS, Beati in Apocalipsin libri duodecim, Roma 1930 (reimp. en Beati in Apocalipsin libri duodecim. Codex Gerundensis. Volumen complementario, Madrid 1975, citaremos por esta reimpresión, pp. 236-239). E. Romero Pose (Sancti Beati a Liebana Commentarius in Apocalypsin, Roma 1985, vol. I, pp. VI-VIII) acepta en su mayor parte las siglas de Sanders. Cuando se refiere a fragmentos no conocidos por Sanders, incorpora las debidas a W. Neuss (Fi).

10 W. NEUSS, Die Apokalypse des Hl. Johannes in der altspanischen und altchristlichen BibelIllustration (Das Problem der Beatus-Handschrisften), Münster 1931, vol. I, pp. 9-61. Las abreviaturas de Neuss son las empleadas por Klein y, entre otros, también por J. WILLIAMS, The illustrated beatus I; The illustrated Beatus, II, The Ninth and Tenth Centuries, London 1994 (en adelante, The illustrated Beatus II), The illustrated Beatus, III, The Tenth and Eleventh Centuries, London 1998 (en adelante, The illustrated Beatus III) y The illustrated Beatus, IV.

11 Respecto a las primeras propuestas, cf. M. C. DÍAZ Y DIAZ, Códices visigóticos en la monarquía leonesa, León 1983, p. 300 e ID., Posición del manuscrito en la tradición textual de los comen- 


\begin{tabular}{|l|l|c|c|}
\hline $\begin{array}{l}\text { El Escorial, Biblioteca del } \\
\text { monasterio, \& II.5 (Olim } \\
\text { III. A. 4; I.H.1) [Beato de El } \\
\text { Escorial] }\end{array}$ & $\begin{array}{l}\text { siglo X ex. / siglo XI in. } \\
\text { ¿San Millán?12 }\end{array}$ & E & E \\
\hline $\begin{array}{l}\text { Gerona, Catedral, ms. 7 } \\
\text { [Beato de Gerona] }\end{array}$ & 975.- Reino de León ¿Tábara?13 & G & G \\
\hline $\begin{array}{l}\text { León, Archivo Parroquial de } \\
\text { Santa Marina la Real, dos } \\
\text { fragmentos sin signatura }\end{array}$ & $\begin{array}{l}\text { siglo X ex./ siglo XI in. } \\
\text { Reino de León'14 }\end{array}$ & - & - \\
\hline $\begin{array}{l}\text { Londres, British Library, } \\
\text { Add. Ms. 11695 [Beato de } \\
\text { Silos] }\end{array}$ & $\begin{array}{l}1091 \text { (escritura) 1109 (ilumina- } \\
\text { ción). Silos }\end{array}$ & $\mathrm{S}$ \\
\hline $\begin{array}{l}\text { Madrid, Academia de la } \\
\text { Historia, Códice 33 [Beato } \\
\text { de San Millán] }\end{array}$ & $\begin{array}{l}\text { Iniciado en el siglo XI in., con- } \\
\text { cluido a finales de siglo. ¿San } \\
\text { Millán?15 }\end{array}$ & $\mathrm{H}$ & $\mathrm{A}^{2}$ \\
\hline
\end{tabular}

tarios: El «Beato» de Saint-Sever (ms. lat. 8878 de la Bibliothèque Nationale de Paris), Madrid 1984, p. 101; A. M. MUNDÓ y M. SÁNCHEZ MARIANA, Catalogación, p. 103. Por lo que se refiere al posible origen facundino, cf. J. A. FERNÁNDEZ FLÓREZ, Fragmentos de un "Beato» del monasterio de Sahagún: Hispania Sacra 35 (1983) 425) e ID., El Apocalipsis y Beato de Liébana. Los ABeatos» y el Beato de Valcavado: Beato de Valcavado. Estudios, Valladolid 1993, p.19, nota 95, J. WILLIAMS, The illustrated Beatus IV, pp. 7 y 17 y P. K. KLEIN, Beatus de Liébana. Codex Urgellensis. Comentario a la edición facsimil, Torrejón de Ardoz (Madrid) 2002, p. 34.

12 Sobre la datación, cf. J. A. FERNÁNDEZ FLÓREZ, Introducción: Beato de Liébana. Original conservado en la Biblioteca del monasterio de El Escorial, Madrid 1995, p. 15, T. MARín MARTínEZ, La escritura de los Beatos: Codex Gerundensis. Volumen complementario, Madrid 1975, pp. 171-210 (citaremos la reimpresión en Studia Paleographica, Diplomatica \& Epigraphica D. Tomás Marín Martínez Magistri Universitatis Complutensis, Madrid, 2001, pp. 477 y 491), A. M. MuNDó y M. SÁNCHeZ MARIANA, Catalogación, p. 104, M. C. DÍAZ Y DÍAZ, La tradición del texto de los Comentarios al Apocalipsis:Actas del Simposio para el estudio de los códices del «Comentario al Apocalipsis» de Beato de Liébana, vol. I, Madrid 1978, p.172, J. WILLIAMS, The illustrated Beatus III, pp. 6 y 29 y P. K. KLeIN, Beatus de Liébana. Codex Urgellensis, p.33. Con respecto al origen geográfico, cf. A. M. Mundó y M. SÁNCHEZ MARIANA, Catalogación, p.104, J. A. FERNÁNDEZ FlóReZ, El Apocalipsis y Beato de Liébana, p. 19, nota 96, P.K. KLEIN, Beatus de Liébana. Codex Urgellensis, p. 33 y J. WILLIAMS, The illustrated Beatus III, pp. 6 y 29.

13 Cf. A. M. Mundó y M. SÁnChez Mariana, Catalogación, p. 106, J. A. Fernández FlóRez, El Apocalipsis y Beato de Liébana, p. 19, nota 95, B. A. SHAILOR, El Beato de Osma, p. 41, M. SÁNCHEZ MARIANA, Introducción histórica: El Beato de Liébana. Códice de Fernando I y Doña Sancha, Barcelona 1994, p. 30, J. WILliAMS, The illustrated Beatus II, pp. 6 y 51, B. A. SHAILOR, Magio y el scriptorium de Tábara: Estudio del manuscrito del Apocalipsis de San Juan Beato de Liébana de San Miguel de Escalada, Valencia 2000, p. 629 y P. K. KLEIN, Beatus de Liébana. Codex Urgellensis, p. 36.

14 Cf. T. BURÓN CASTRO, Fragmento de Beato, p. 134.

15 «de ambiente marcadamente emilianense» (M. C. DíAZ Y DÍAZ, Libros y librerías en la Rioja altomedieval, Logroño 1979, p. 209). «Quizá sea oriundo de San Millán o, al menos, de un taller próximo" (E. RuIZ GARCÍA, Real Academia de la Historia. Catálogo de la sección de códices, Madrid 1997, p. 237).

Textos medievales

Hispania Sacra 55 (2003) 


\begin{tabular}{|c|c|c|c|}
\hline $\begin{array}{l}\text { Madrid, Archivo Histórico } \\
\text { Nacional, Cod.1097 (Vit.35, } \\
\text { n. 257; 1240B) [Beato de } \\
\text { Tábara] }\end{array}$ & $\begin{array}{l}970 \\
\text { Tábara (Zamora) }\end{array}$ & A & $\mathrm{T}$ \\
\hline $\begin{array}{l}\text { Madrid, Biblioteca Nacio- } \\
\text { nal, ms. Vitr.14-1 (Olim } \\
\text { Hh.58) [Beato Vitrina 14-1] }\end{array}$ & $\begin{array}{l}\text { Siglo } X_{¿ \text { inicios? ¿mediados? }} \\
\text { ¿Castilla, región burgalesa o } \\
\text { riojana? ¿sur o sudeste del reino } \\
\text { de León?16 }\end{array}$ & $\mathrm{N}$ & $\mathrm{A}^{1}$ \\
\hline $\begin{array}{l}\text { Madrid, Biblioteca Nacio- } \\
\text { nal, ms. Vitr.14-2 (Olim } \\
\text { B.31) [Beato de Fernando I } \\
\text { y doña Sancha] }\end{array}$ & $\begin{array}{l}1047 \\
\text { ¿León? }{ }^{17}\end{array}$ & M & $\mathbf{J}$ \\
\hline $\begin{array}{l}\text { Madrid, Biblioteca Nacional, } \\
\text { ms. Vitr.14-2 (fragmento) }{ }^{18}\end{array}$ & $\begin{array}{l}\text { siglo X, último tercio } \\
\text { Reino de León ¿Valcavado? }{ }^{19}\end{array}$ & $-[\mathrm{Fi}]$ & $\mathrm{Fi}$ \\
\hline $\begin{array}{l}\text { Montserrat, Biblioteca de la } \\
\text { Abadía, } 793 \text { VIII + Vallado- } \\
\text { lid, Archivo de la Real Chan- } \\
\text { cillería, Pergaminos, carpeta } \\
80 \text {, n.9 y } 8 \text { (fragmentos) }\end{array}$ & $\begin{array}{l}\text { siglo XI, último cuarto } \\
\text { Probablemente Sahagún }{ }^{20}\end{array}$ & - & - \\
\hline
\end{tabular}

16 A propósito de la fecha, cf. P. K. KLEIN, Der ältere Beatus-Kodex Vitr. 14-1 der Biblioteca Nacional zu Madrid. Studien sur Beatus-Illustration und der spanischen Buchmalerei des 10. Jahrhunderts. I, Hildesheim- New York 1976 pp. 271-272 y 290-297 lo databa entre c. 920 y mediados de la centuria. Recientemente, este investigador lo considera «realizado hacia el 930-950» (P. K. KLEIN, Beatus de Liébana. Codex Urgellensis p. 34). Respecto a las propuestas de origen grográfico M. C. DÍAZ Y DÍAZ, Libros y librerias, pp. 227-228 y P. K. KLEIN, Der ältere Beatus-Kodex Vitr. 14-1, I, pp. 290-297 e ID., Beatus de Liébana. Codex Urgellensis, p. 34.

17 Cf. M. SÁNCHEZ MARIANA, Introducción histórica, p.46. Es fruto del scriptorium real leonés para J. Williams, The illustrated Beatus III, p. 34 y P.K. KLEIN, Beatus de Liébana. Codex Urgellensis, p. 35).

18 Admitido por la mayor parte de los investigadores que los cinco folios iniciales de Madrid, Biblioteca Nacional, Vitr. 14-2 son un fragmento de otro Beato - razón por la cual los consideramos pieza independiente en este cuadro- M. Sánchez Mariana indica, sin embargo, que el códice Vitr. 14-2 «parece obra de una sola mano» (M. SÁNCHEZ MARIANA, Introducción histórica, Barcelona 1994, p. 55).

19 Postula el «Reino de León» J. WILliAMS, The illustrated Beatus II, pp. 6 y 65. «Son del Beato de Valcavado» (A. Millares Carlo, Corpus de códices visigóticos. I. Estudio (ed. de M.C. Díaz y Díaz, A.M. Mundó, J.M. Ruiz Asencio, B. Casado Quintanilla y E. Lecuona Ribot), Las Palmas de Gran Canaria 1999, p. 100).

20 Cf. J. A. FERnÁNDEZ FlóREZ, Fragmentos, p. 425 e ID., El Apocalipsis y Beato de Liébana, p.19, nota 95 . 


\begin{tabular}{|c|c|c|c|}
\hline $\begin{array}{l}\text { New York, Pierpont Morgan } \\
\text { Library, ms. } 644 \text { [Beato } \\
\text { Morgan, Beato de Magio, } \\
\text { Beato de San Miguel de } \\
\text { Escalada] }\end{array}$ & $\begin{array}{l}\text { siglo X, mediados } \\
\text { ¿Tábara? ¿San Miguel de Escala- } \\
\text { da?21 }\end{array}$ & $\mathrm{Y}$ & $\mathrm{M}$ \\
\hline $\begin{array}{l}\text { San Pedro de las Dueñas } \\
\text { (León), Archivo del } \\
\text { Monasterio, fragmento } 1 \\
\end{array}$ & $\begin{array}{l}\text { siglo } \mathrm{X} \text { in. } \\
\text { Región leonesa }^{22}\end{array}$ & - & - \\
\hline $\begin{array}{l}\text { Seo de Urgel, Catedral, } \\
\text { códice } 4 \text { [Beato de Urgel] }\end{array}$ & $\begin{array}{l}\text { siglo X, último cuarto o finales, } \\
\text { Siglo XI in. } \\
\text { ¿León? ¿La Rioja? ¿Navarra? } \\
\text { ¿Aragón? } 23 .\end{array}$ & $\mathrm{U}$ & $\mathrm{U}$ \\
\hline $\begin{array}{l}\text { Silos, Biblioteca del Monas- } \\
\text { terio, fragmentos 1-3 }\end{array}$ & $\begin{array}{l}\text { siglo X, segunda mitad o finales }{ }^{24} \\
\text { origen desconocido }\end{array}$ & $-[\mathrm{F}-\mathrm{Fc}]$ & F \\
\hline $\begin{array}{l}\text { Silos, Biblioteca del Monas- } \\
\text { terio, fragmento } 4\end{array}$ & $\begin{array}{l}\text { siglo IX ex. } \\
\text { ¿Navarra? ¿Aragón? ¿Asturias?25. }\end{array}$ & - & $\mathrm{Fc}$ \\
\hline
\end{tabular}

${ }^{21}$ Datación defendida, entre otros, por M. C. DÍAZ Y DÍAZ, Códices visigóticos, p. 338, T. MARÍN MARTíneZ, La escritura, p. 492, P.K. KLEIN, Beatus de Liébana. Codex Urgellensis, pp. 25-35, M. SÁNCHEZ MARIANA, Introducción histórica, p. 30, B. A. SHAILOR, Análisis codicológico: El Beato de San Miguel de Escalada, Madrid 1991, p. 29 y J. WILliaMS, Introducción al manuscrito: Estudio del manuscrito del Apocalipsis de San Juan Beato de Liébana de San Miguel de Escalada, Valencia 2000, p. 574). No podemos ocultar la opinión discrepante de V. García Lobo, partidario de fechar este beato en «el año 922 de nuestra era» (V. GARCÍA LOBO, El Beato de San Miguel de Escalada: Archivos Leoneses 33 (1979) 262, ID., Archivos Leoneses y la investigación histórica: Archivos Leoneses 99-100 (1996) 105 e ID., Colección documental del monasterio de San Miguel de Escalada (904-1605), León 2000, p. 364). En cuanto al lugar de nacimiento, se decantan por un origen tabarense, entre otros, J. WILLIAMS, The illustrated Beatus II, pp. 6 y 21 e Introducción al manuscrito, p.574, J. A. FERNÁNDEZ FLÓREZ, El Apocalipsis y Beato de Liébana, p. 19, nota 95 y Los comentarios al Apocalipsis de Beato de Liébana: En torno al Apocalipsis, Madrid 2001, p. 141 (nota 44), B. A. SHAILOR, Magio y el scriptorium de Tábara: Estudio del manuscrito del Apocalipsis de San Juan Beato de Liébana de San Miguel de Escalada, Valencia 2000, pp. 625-631 e ID., Análisis codicológico, p. 24. El monasterio de Escalada es la cuna del ejemplar según V. GARCía LOBO, El Beato, ID., Archivos Leoneses, p. 106 e ID., Colección documental, p. 364.

22 Cf. M.C. DÍAZ Y DÍAZ, Un nuevo fragmento de Beato: León y su Historia, IV, León 1977, p. 17.

${ }^{23}$ Cf M.C. DíAZ Y DíAZ, La tradición, p. 172, J. WilliAMS, The illustrated Beatus III, pp. 6 y 17 y P.K. KLEIN, Beatus de Liébana. Codex Urgellensis, pp. 21, 24 y 28.

24 Cf. M. C. DíAZ y DíAZ, Libros y librerías, p. 47 y A. M. Mundó y M. SÁNCHEZ MARIANA, Catalogación, p. 123.

${ }^{25}$ Las propuestas de datación en M. C. DíAZ Y DíAZ, Libros y librerías, pp. $46-47$ e ID., La tradición, p. 169, A. M. MUNDÓ, Sobre los códices de Beato: Actas del Simposio para el estudio de los códices del «Comentario al Apocalipsis» de Beato de Liébana, vol. I, Madrid 1978, p. 115, A. M. Mundó y M. SÁNCHEZ MARIANA, Catalogación, p. 123, J. Williams, The illustrated Beatus II, pp. 6 y 17 y P.K. KLEIN, Beatus de Liébana. Codex Urgellensis, p. 34. «Salido de un escriptorio pirenaico, quizá navarro o algo más oriental» para M. C. DÍAZ Y DíAZ, Libros y librerías, p. 47. «)PirineosAragón?» es el territorio apuntado como origen en A. M. MUNDÓ y M. SÁNCHEZ MARIANA, Catalo-

Textos medievales

Hispania Sacra 55 (2003) 


\begin{tabular}{|l|l|l|l|}
\hline $\begin{array}{l}\text { Valladolid, Biblioteca de la } \\
\text { Universidad, ms. 433 } \\
\text { [Beato de Valcavado o } \\
\text { Beato de Valladolid] }\end{array}$ & $\begin{array}{l}970 \\
\text { Valcavado (Palencia) }\end{array}$ & V & V \\
\hline $\begin{array}{l}\text { Zamora, Archivo Histórico } \\
\text { Provincial, fragmentos 276 } \\
\text { y } 277\end{array}$ & & - & - \\
\hline $\begin{array}{l}\text { Zaragoza, Colección Cane- } \\
\text { llas + colección particular } \\
\text { (lugar de conservación } \\
\text { desconocido). Fragmentos }\end{array}$ & & & \\
\hline
\end{tabular}

Es fácil introducir el Beato del Archivo Histórico Provincial zamorano en una tabla que recoge los ejemplares visigóticos ordenados de acuerdo a un criterio alfabético-toponímico, tomando como referencia los lugares de conservación actual de las piezas. Mayores problemas plantea insertar el nuevo Beato en el complejísimo stemma de los testigos de la obra. Para lograr este objetivo hay que fijar con la mayor precisión posible el origen, la edad del manuscrito y la tradición de su texto, teniendo en cuenta que, como señalábamos en otra ocasión, «son tantas las discrepancias entre los expertos cuando pretenden fijar las coordenadas espacio-temporales en las que se sitúan manuscritos con señas de identidad aparentemente claras, que ubicar en el tiempo $\mathrm{y}$ en el espacio piezas aisladas como las que ahora nos interesan parece, en principio, un objetivo imposible» ${ }^{26}$. En efecto, como revelan las numerosas interrogaciones en el cuadro precedente, aún no hay acuerdo sobre la fecha y el lugar en el que se materializaron varios de los beatos anteriormente citados.

Conscientes de las dificultades para determinar el origen de nuestro beato, intentaremos, no obstante, una aproximación por diferentes caminos.

\section{EL CAMINO DE LA FORMA.}

Entendiendo ahora bajo el término forma únicamente los «caracteres externos» de los fragmentos ${ }^{27}$, veamos a dónde nos conducen algunos aspectos vin-

gación, p. 123. Al norte de España - ¿Asturias? - lo adscriben J. WILLIAMS, The illustrated Beatus II, pp. 6 y 17 y P.K. KLEIN, Beatus de Liébana. Codex Urgellensis, p. 34.

26 A. SuÁrez GonZÁlez, Dos folios, p.305..

27 Generalmente, diferenciamos en la forma de un libro «dos grandes apartados: caracteres externos y caracteres internos» (...) Los caracteres externos corresponden a «la materialidad del libro» (A. SUÁREZ GONZÁLEZ, Patrimonio cultural de San Isidoro de León. B. Serie bibliográfica. II. Los códices III.1, III.2, III.3, IV y V (Biblia, Liber capituli, Misal), León 1997, p. 21). 
culados a su materialidad - dimensiones, mise en page y escritura- si establecemos una comparación con los restantes testigos visigóticos.

Son las dos piezas pergaminos amarillentos. En la membrana, bien acondicionada para recibir escritura, se diferencian nítidamente la faz del pelo (276r y $277 \mathrm{v}$ ) - más oscura - y la de la carne. Con contorno irregular, debido a su deterioro, mide el fragmento $276334 \times 254 \mathrm{~mm}$ y el fragmento $277331 \times 251 \mathrm{~mm}$. Los folios del Beato al que remiten los dos testigos del A.H.P. zamorano medían, al menos, $334 \times 254 \mathrm{~mm}$. Nos hallaríamos, por tanto, ante un códice de formato análogo ${ }^{28}$ al de otros ejemplares visigóticos como el Beato de Tábara, el de San Millán, el Beato Vitrina 14-1 y el códice de Valcavado ${ }^{29}$.

Por lo que se refiere a la mise en page ${ }^{30}$, conviene que destaquemos los siguientes aspectos: la morfología y disposición de los regímenes de pinchazos, el procedimiento, sistema y tipo del pautado y el número de rectrices.

En los fragmentos 276 y 277 se practicaron, realizando la perforación de recto a vuelto, orificios planos o alargados: pinchazos maestros en los márgenes de cabeza y pie y pinchazos-guía de las directrices en el centro del folio (espacio del intercolumnio ${ }^{31}$ ). Este régimen intercolumnar se aprecia también en varios manuscritos visigóticos: el fragmento 4 del Archivo del Monasterio de Silos ${ }^{32}$, el fragmento de Beato que se halla en el Archivo del Monasterio de San Pedro de las Dueñas (León) ${ }^{33}$, el Beato de Magio $^{34}$, el Beato de Tábara ${ }^{35}$, el Beato de Gerona, el Beato de Fernando ${ }^{36}$, los fragmentos del Archivo Parroquial de Santa Marina la Real (León), en, aproximadamente, la mitad de los

28 Aportamos las dimensiones extremas o máximas y para realizar la comparación tomamos como referencia la talla o medio perímetro, que en el caso de los folios zamoranos es de $588 \mathrm{~mm}$ en el fragmento 276, menos recortado, y de $582 \mathrm{~mm}$ en el fragmento 277 .

29 Son libros con talla que oscila entre 580 y $600 \mathrm{~mm}$. Sólo uno de los ejemplares visigóticos aceptablemente conservados tiene menores dimensiones (Escorial, Biblioteca del Monasterio, \& II.5). Sensiblemente mayores son los siguientes beatos: Osma, Gerona, Vitr. 14-2, Vit.14-2, fragmento, Morgan y Urgel.

30 Advertimos que sólo hemos podido analizar directamente estos aspectos en Madrid, Archivo Histórico Nacional, Códice 1097 B; Madrid, Biblioteca de la Academia de la Historia, Códice 33; Madrid, Biblioteca Nacional, ms. Vitr. 14-1 y en los cuatro fragmentos conservados en el archivo silense.

31 Perforaciones levemente descentradas si tomamos como referencia el intercolumnio. En el f.276r los pinchazos-guía se hallan a $12 \mathrm{~mm}$ de la vertical que delimita por la derecha la primera columna de texto y a $9 \mathrm{~mm}$ de la línea que cierra por la izquierda la segunda columna.

32 Los pinchazos-guía son, a diferencia de sus correspondientes zamoranos, de morfología circular.

33 Las perforaciones-guía de las directrices son también planas. Nos basamos en la descripción y en la reproducción fotográfica que recoge M.C. DÍAZ Y DÍAZ, Un nuevo fragmento de Beato, p. 11.

34 Cf. B. A. SHAILOR, Análisis codicológico, p. 24.

35 Hemos comprobado cómo difiere a lo largo del manuscrito la morfología de estas picaduras intercolumnares. Predominan las planas, pero en los cuadernos finales tienen forma redonda.

${ }^{36}$ Las perforaciones tienen morfología circular.

Textos medievales

Hispania Sacra 55 (2003) 
cuadernos del Beato Vitr. 14-1 $1^{37}$ y, también, en parte de los códices de $O s m a^{38}$ y de Valcavado ${ }^{39}$.

Se advierte en los pergaminos zamoranos un pautado a punta seca, con el surco de las líneas en el recto de ambas piezas $\left(>->_{-}\right)$. El procedimiento de pautado en surco/relieve es el habitual en los otros manuscritos visigóticos. Con respecto al sistema -incisión sobre el recto- contamos con menor información ${ }^{40}$. En la mayor parte de los beatos parece ser que el surco de las líneas se localiza sobre la cara pelo del pergamino, corresponda ésta al recto o al vuelto del folio. Por esta razón, únicamente se asemejarían a los fragmentos que nos ocupan el Beato de la Real Academia de la Historia ${ }^{41} \mathrm{y}$, parcialmente, el Beato de San Miguel de Escalada ${ }^{42}$. El tipo del pautado establece dos columnas delimitadas externamente por doble vertical e intercolumnio definido por verticales simples. Las maestras parecen prolongarse hasta los bordes superior e inferior de los folios. Se completa el entramado con 31 rectoras que atraviesan el intercolumnio (UR de aproximadamente $8 \mathrm{~mm})^{43}$.

Coincide el tipo de pautado de los folios zamoranos con el que se dispone en los siguientes beatos visigóticos: Beato Vitr. 14-1, Beato de Fernando I, Beato de Osma y, sólo parcialmente, en el Beato de Magio $^{44}$ y el manuscrito de Urgel ${ }^{45}$.

${ }^{37}$ A partir del f.75 los pinchazos son intercolumnares. Generalmente más pequeños que los dispuestos en los fragmentos zamoranos, la forma de las punciones varía a lo largo del manuscrito, unas veces son alargadas y otras circulares.

38 Predominan en este libro las perforaciones dispuestas en el interior de la columna de texto más próxima al canal. Sin embargo, desde el f. 42 hasta el 79, ambos inclusive, los pinchazos - de morfología circular - se advierten en el intercolumnio, constituyendo una hilera torcida.

${ }^{39}$ La ubicación de los pinchazos - guía varía a lo largo del volumen y la morfología de las perforaciones es circular.

${ }^{40} \mathrm{La}$ restauración de la que han sido objeto algunos de los manuscritos impide en ciertos casos determinar el sistema, lo que se constata, por ejemplo, en Madrid, Archivo Histórico Nacional, Cod.1097. Por otra parte, este aspecto rara vez se puede deducir con claridad a partir de facsímiles y no se recoge en algunas de las descripciones editadas hasta la fecha.

41 Cf. E. Ruiz GarCía, Catálogo, p. 678.

42 Así lo indica B. A. SHAILOR, Análisis codicológico, p. 24.

43 En la figura 1 representamos la parte de las rectas que se aprecia con dificultad por medio de línea discontinua. La figura, correspondiente al fragmento $276 \mathrm{r}$, responde a la siguiente descripción de la página (en mm): $20+6+67+21+69+6+65 \times 24+245+65(\mathrm{UR}=8,166 \mathrm{~mm})$. El fragmento $277 \mathrm{r}$ se ajusta a la siguiente descripción (en mm): $15+6+66+20+69+6+69 \times 26+243+62$ (UR=8,1).

44 En los ff. 294-299, según B. A. SHAILOR, Análisis codicológico pp. 24-25.

45 Varían, lógicamente, de unos manuscritos a otros, la anchura de las columnas, del intercolumnio, de los márgenes, etc. Sorprende, no obstante, el estrecho intercolumnio del Beato de Osma, con las mismas dimensiones que el de los fragmentos zamoranos. 


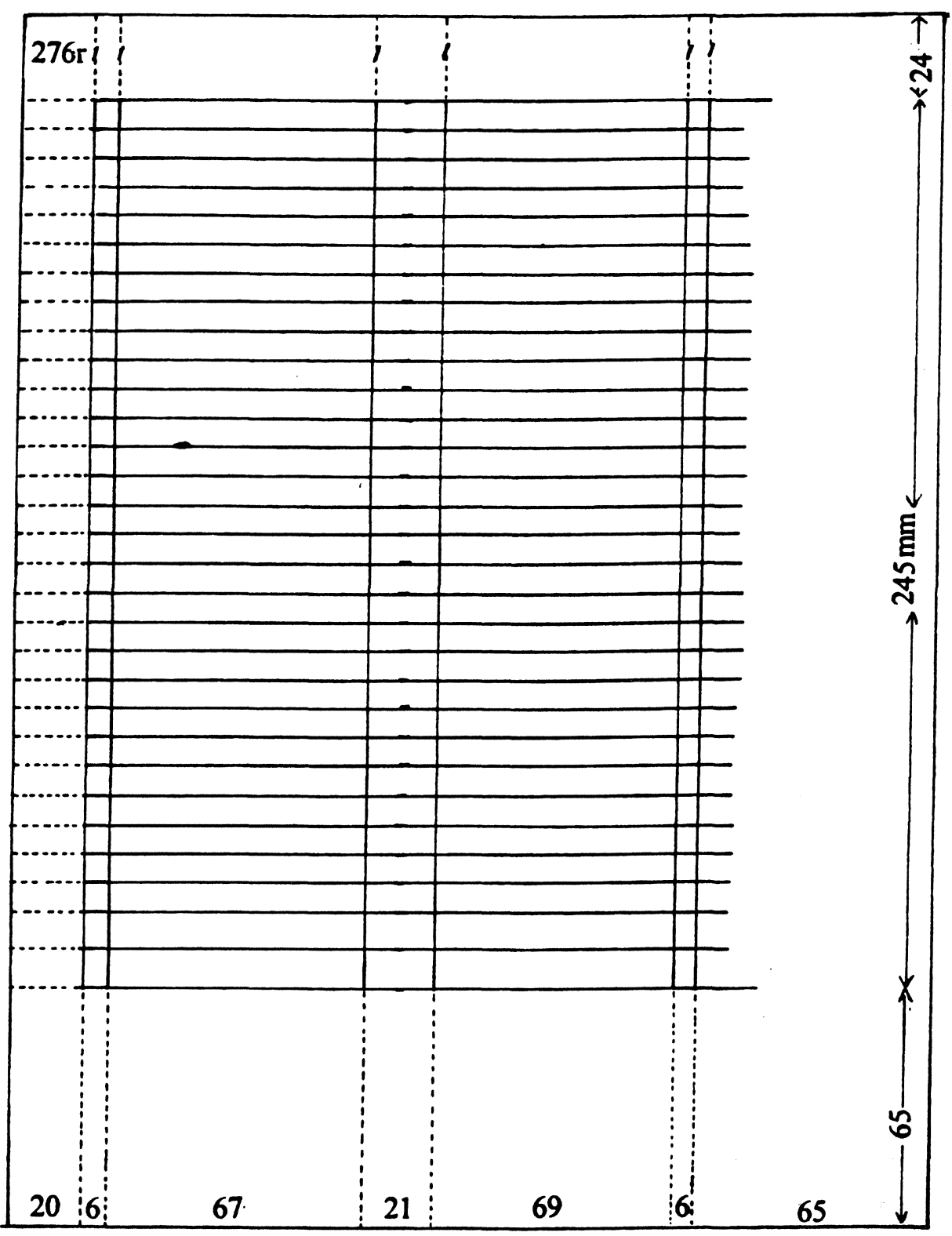

Fig. 1

Textos medievales

Hispania Sacra 55 (2003) 
Son 31 las rectrices trazadas sobre los fragmentos que nos ocupan. Aun admitiendo que ciertos códices visigóticos presentan irregular número de rectoras $^{46}$, el Beato de Zamora es, junto al fragmento 4 del Monasterio de Silos ${ }^{47}$, el que cuenta con menos renglones por página ${ }^{48}$.

A excepción del renglón $8^{\circ}$ en la segunda columna del fragmento $276 \mathrm{v}$, la tinta utilizada para la escritura es marrón. Los caracteres del citado renglón - correspondiente a un pasaje del Apocalipsis - se realizaron en rojo, comportamiento también habitual en los restantes Comentarios visigóticos.

La escritura, obra de una sola mano, es visigótica redonda, bien ejecutada y de fácil lectura, pese a la irregular separación de palabras.

La longitud de los caídos y los astiles - abultados, generalmente biselados - confiere esbeltez a las letras. Por lo que se refiere a la inclinación, en los astiles se advierte una leve tendencia levógira y los caídos revelan una cierta indecisión, si bien predominan los dextrógiros. La diferenciación $t i / t j$ se observa en la mayor parte de los ejemplos ${ }^{49}$. Los remates de los trazos verticales de las letras $h, m, n$ minúsculas se orientan hacia la derecha. Sobresale la $i$ por su variedad morfológica: corta, con remate que se dirige a la derecha; $i$ rematada en punta, de diversa longitud, perpendicular al renglón o curvada hacia la izquierda en el pie e $I$ alta en posición inicial y en el interior de palabra cuando tiene valor de iod. En las mayúsculas se mezclan las formas unciales con las capitales. Algunas letras $(A, E, Q)$ presentan morfologías de ambas tradiciones. Aparecen los nexos $i T$ a final de renglón y $n T$ a final de palabra, sea cual sea la posición de ésta. Signo general de abreviación es el trazo horizontal dispuesto sobre las letras bajas o cortando el astil de las altas. Este mismo trazo con punto sobrepuesto suple $m$ y, sólo excepcionalmente, $n$. El semicolon sustituye ue tras $q$ y $u s$ cuando se asocia a $b, i$ alta y $n$. Para abreviar per se incorpora a la $p$ el signo con remate en forma de bucle, trazo que arranca del punto de corte entre el ojo de la consonante y el caído. Se recurre, irregularmente, a la e cau$d a d a$. Para notarla, se une a la parte inferior de la vocal una pequeña $q$. El final - $u m$ tras $r$ se sustituye por medio de un trazo ligeramente curvo que corta perpendicularmente bien la prolongación del segundo rasgo en la $r$ de martillo, bien - excepcionalmente - el trazo de fuga de la $r$ redonda. Por lo que se refiere a

46 Es el caso, por ejemplo, del Beato de Tábara, los manuscritos Vitr. 14-1 y Vitr. 14-2, el Beato Morgan, el Beato de Urgel y el Beato de Valcavado.

47 J. WILLIAMS, The illustrated Beatus II, ills. 1-2.

$48 \mathrm{El}$ número de renglones por página en los restantes ejemplares visigóticos oscilaría entre los 32 y los 43 (cf. A. M. MUNDó y M. SÁNCHEZ MARIANA, Catalogación, pp. 103, 104, 106, 109-114, $117,118,121-123,125$ y $126, \mathrm{n}^{\text {os }} 3,4,6,10-15,19,21,25,27,28,29,32$ y 34$)$.

49 Véanse las características de la $i$ en el grupo $t j$ y las excepciones en A. SUÁREZ GONZÁLEZ, Dos folios, p. 292. 
las palabras abreviadas ${ }^{50}$, destacan las suspensiones de $m$ final, y las de dos letras (er, ue, um, us) suplidas por los signos especiales anteriormente descritos. También aparecen contracciones y son escasísimas las abreviaturas mixtas.

Las características descritas situarían la escritura entre el denominado periodo «de mejoría y perfeccionamiento» ${ }^{51}$ y el considerado «de perfección» ${ }^{52}$ en el desarrollo de la visigótica sentada libraria.

Ya a primera vista, atendiendo al trazado, la proporción y algunas peculiaridades morfológicas de los signos, la escritura de nuestros dos folios presenta sustanciales diferencias con la grafía notablemente más esbelta, de largos astiles en cuyo extremo se sitúan finos largos oblicuos, que tapiza las páginas de los fragmentos 1-3 de Silos y el Beato escurialense ${ }^{53}$. Teniendo en cuenta, además de los aspectos anteriores, ciertos rasgos que permiten establecer una evolución en la visigótica redonda, observamos grandes desemejanzas entre la grafía de los folios zamoranos y la - sensiblemente más evolucionada y de tratamiento más rígido - que se localiza en los pequeños fragmentos recientemente descubiertos en el Archivo Parroquial de Santa Marina la Real de León ${ }^{54}$, los cinco folios de un mismo ejemplar repartidos hoy entre el monasterio de Montserrat y la Real Chancillería de Valladolid, el Beato de la Academia de la Historia y, muy especialmente, el Beato de Silos, manuscrito que destaca por su caligrafía recargada con demasiados rasgos de adorno. En otro extremo cabría situar los caracteres del fragmento 4 del archivo silense, más arcaicos que los dispuestos en los folios zamoranos, y los de la pieza conservada en el Archivo del Monasterio de San Pedro de las Dueñas (León). El engrosamiento en el arranque de las astas, aproximaría la escritura de los fragmentos zamoranos a la de los beatos de Valcavado, Tábara, Gerona, Fernando I y Urgel ${ }^{55}$. Sin embar-

50 El número y las características de las abreviaturas pueden observarse en la transcripción del texto que recogemos en el Apéndice puesto que se indican las letras abreviadas por medio de caracteres cursivos.

51 Cf. T. MARÍN MARTÍNEZ, La escritura, p. 487.

52 Ibidem, p. 488.

53 En las observaciones sobre la escritura de estos y otros ejemplares visigóticos abordaremos la grafia globalmente, sin diferenciar las distintas manos intervinientes, salvo cuando advirtamos entre ellas grados de evolución muy distintos.

54 T. BURón CASTRO, Fragmento de Beato.

55 Refiriéndose a las variedades de la escritura visigótica libraria, señala el profesor Millares: «la leonesa -más esbelta y estrecha, de arcos más altos y trazos ligeramente abultados en sus extremos superiores» (...) «Se trata, desde luego, de un grafismo en esencia semejante al que encontramos en los Beatos tabarense y gerundense, obra en parte el primero, y en su totalidad el segundo, de Senior, tan vinculado al referido cenobio leonés, así como en los de Valcavado, del año 970, hoy en la Biblioteca Universitaria de Valladolid, y el de la Seo de Urgel, que nos parece muy difícil atribuir, aun dubitativamente, al área de la Rioja» (A. MILlARES CARLO, Problemas que suscita la escritura de los Beatos:Actas del Simposio para el estudio de los códices del «Comentario al Apocalipsis» de Beato

Textos medievales

Hispania Sacra 55 (2003) 
go, ciertos signos de abreviación, la diferenciación sistemática ti/tj, separación de palabras, etc. indican que la visigótica sentada de estos ejemplares es más evolucionada que la de los folios del A.H.P. de Zamora.

Las similitudes son más evidentes con el beato de Magio ${ }^{56}$. La escritura de las piezas zamoranas y la del ejemplar de Escalada, comparten, entre otros aspectos, los astiles abultados y biselados en el arranque y la cauda de la $e$ con forma de pequeña $q$.

Pero, sin duda, el beato con el que mayores analogías hallamos es Madrid, Biblioteca Nacional, ms. Vitr. 14-1, en concreto, con la obra gráfica del copista principal ${ }^{57}$. Se observan semejanzas notables en la morfología de los caracteres alfabéticos aislados, en la $u$ angular sobrepuesta, en los nexos, en la cauda de la $e$, en signos de abreviación, en la inclinación irregular de las letras, en la disposición de éstas sobre la pauta, en el abultamiento de los astiles - bastante largos-, en la deficiente separación de palabras - que confiere al conjunto gráfico cierto abigarramiento-, etc. Pese a tantas similitudes, no podemos afirmar que los dos beatos sean obra de un mismo copista. El escasísimo conjunto gráfico superviviente en los fragmentos de Zamora, impide comprobar si, al igual que en el Vitr.14-1, también en el beato al que remiten se empleó $A$ capital sin trazo horizontal ${ }^{58}$, se utilizó ocasionalmente la $a$ cursiva o la abreviatura per con trazo horizontal cortando el caído de la consonante o con rasgo quebrado dirigido hacia la izquierda.

Es, precisamente, la escritura de este maltrecho volumen de la Biblioteca Nacional — suponemos que únicamente la debida a la mano principal— la que toma como ejemplo T. Marín para describir las características de la visigótica redonda en su segundo periodo, en el que esta escritura «empieza a perfeccionarse» y que abarca el «final del siglo IX y la primera mitad del siglo $\mathrm{X} »^{59}$ :

\footnotetext{
de Liébana, vol. I, Madrid 1978, pp.204-205). Véase también A. Millares CARLO, Tratado de Paleografia Española, vol.I. Texto, Madrid 1983, p. 135).

56 Obra de dos manos, cf. B.A. SHAILOR, Análisis codicológico, pp. 26-28.

57 La labor de una segunda mano, netamente distinta, se caracteriza por la excesiva longitud de los astiles y el menor módulo de los caracteres. Es, además, más evolucionada, y nos recuerda la escritura de otras obras posteriores como el Beato del Escorial. Puede verse una descripción pormenorizada del ejemplar en P. K. KLEIN, Der ältere Beatus-Kodex Vitr. 14-1 der Biblioteca Nacional zu Madrid. Studien zur Beatus-Illustration und der spanischen Buchmalerei des 10. Jahrhunderts, I, Hildesheim-New York 1976 y reproducciones fotográficas en las que se aprecian las diferentes escrituras en P. K. KLEIN, Der ältere Beatus-Kodex Vitr. 14-1 der Biblioteca Nacional zu Madrid. Studien zur Beatus-Illustration und der spanischen Buchmalerei des 10. Jahrhunderts, II. Tafelband, Hildesheim-New York 1976.

58 Morfología predominante de la mayúscula en Vitr.14-1. Sin embargo, en las piezas zamoranas, la $A$ cuenta siempre con trazo horizontal.

59 T. MARÍN MARTÍNEZ, La escritura, p. 484.
} 


\begin{abstract}
«letras de módulo pequeño, pero relativamente limpias, correctas y bien proporcionadas, con nexos escasos, aunque todavía un poco desmesuradas entre su alto y su ancho (...) Los palos altos no se espesan ya bastamente y los finales de $m$ y $n$ inician hacia afuera un giro gracioso. Se mejora bastante en punto a separación de palabras; y en cuestión de signos abreviativos hay algún leve cambio, por ejemplo para representar us y $u$; ; aparece con regularidad el signo de interrogante, y es frecuente, si no habitual, en el nexo $t i$ la forma de $i$ alargada ${ }^{60}$.
\end{abstract}

Carentes ambos folios de iluminación ¿qué coordenadas espacio-temporales nos permite fijar el camino de la forma?

El soporte, las dimensiones de los folios y la mise en page no proporcionan información útil para nuestro propósito pues, como hemos comprobado, beatos claramente distanciados en tiempo y espacio coinciden con los fragmentos zamoranos en aspectos tales como disposición y morfología de los pinchazos, sistema, tipo del pautado, etc. Respecto a la escritura, tomando en consideración el grado de evolución de la letra visigótica, los fragmentos del A.H.P de Zamora serían posteriores al fragmento 4 de Silos y, quizá, al fragmento 1 de San Pedro de las Dueñas. Creemos que pueden considerarse coetáneos al Beato Vitr.14-1 y anteriores a los restantes testigos visigóticos, de los cuales el más próximo, a nuestro juicio, sería el Beato de San Miguel de Escalada. La letra situaría al beato del que proceden las piezas zamoranas entre los cuatro más antiguos testigos de la obra, en la primera mitad del siglo X.

Mayores problemas plantea la determinación de una coordenada espacial, debido en buena parte a la temprana fecha que atribuimos a los fragmentos y a la probable itinerancia de los artífices de libros en un amplio ámbito geográfi$\mathrm{co}^{61}$. Considerando algunas peculiaridades morfológicas, los fragmentos de Zamora se aproximaban, decíamos, a beatos tenidos por leoneses, como los códices de Fernando I y Sancha, Gerona, San Miguel de Escalada, Tábara, Valcavado y, con mayores dudas, Urgel. Este hecho permitiría situar la cuna del beato del A.H.P. zamorano en un scriptorium sito en territorio sur o sudoriental del Reino de León. Sin embargo, como señalábamos anteriormente, el manuscrito más cercano en lo que atañe a la escritura es el problemático y, por el momento, «apátrida» Beato Vitr.14-1.

60 Ibidem, p.487.

61 Recojamos la opinión de M. C. Díaz y Díaz, para el cual «como prueba su escritura, Magio era castellano» (M. C. DÍAZ Y DíAZ, La tradición, p. 177). Sin embargo, parece fuera de toda duda la vinculación de este calígrafo y miniaturista con monasterios leoneses. Como asevera J. A. Fernández Flórez: «A pesar de los trabajos de excelentes especialistas no se ha llegado a identificar lo que es peculiar y, en consecuencia, distingue, a cada uno de los grandes escritorios castellano-leoneses; de ahí que aunque cada día sepamos más cosas sobre viajes de manuscritos y calígrafos (obras de Florencio, desplazamientos de Magio, etc...) Se sigue discutiendo sobre los lugares que dieron a luz numerosos códices visigóticos, entre ellos algunos Beatos» (J. A. FERNÁNDEZ FLÓREZ, Fragmentos, p. 409, nota 35).

Textos medievales

Hispania Sacra 55 (2003) 


\section{EL CAMINO DEL TEXTO.}

Si pretendemos insertar los dos fragmentos o, mejor dicho, el ejemplar al que remiten, en el stemma de los beatos, tomando como base el contenido, tropezamos con tres obstáculos: la escasez del texto superviviente - teniendo en cuenta la magnitud de la obra exegética-, la mala conservación de las piezas y la falta de total acuerdo entre los expertos en la tradición textual cuando pretenden dibujar el árbol genealógico de los manuscritos.

Por lo que se refiere al primer aspecto, sobrevive en los fragmentos sólo parte del libro tercero de los Comentarios al Apocalipsis atribuidos a Beato de Liébana y, además, entre ambas piezas se advierte una laguna que, creemos, equivale al contenido de dos folios. El texto conservado en el fragmento 276 corresponde a Beati in Apocalipsin III, 3, 106-117 (edición de H. A. Sanders ${ }^{62}$ ) o III, pp. 496 (3-22)-500 (1) tomando como referencia la edición de E. Romero Pose $^{63}$. El fragmento 277 recoge Beati in Apocalipsin III, 4, 11-24 (edición de H. A. Sanders) o pp. 509 (7-19) - 513 (14) según la edición de E. Romero. Las conclusiones a las que lleguemos, partiendo de base textual tan reducida, forzosamente habrán de ser presentadas con reservas.

Un primer paso en el recorrido lo proporciona el cotejo del texto con su correspondiente en las dos ediciones críticas del Comentario al Apocalipsis ${ }^{64}$ anteriormente citadas, la publicada por H. A. Sanders en 1930 y la debida a E. Romero Pose en $1985^{65}$. Considerando la edición de H. A. Sanders, sólo serían

62 H. A. SANDERS, Beati in Apocalipsin libri duodecim, pp. 549-552.

63 E. ROMERo Pose, Sancti Beati a Liebana Commentarius in Apocalypsin, Roma 1985, vol. I.

64 Advertimos «ediciones críticas», entendiendo por tales las que se basan en manuscritos de la obra. Hemos de citar, no obstante, otras dos posteriores que no son útiles para nuestro objetivo. En primer lugar la aparecida en 1995 , pues, como señalan sus autores «El texto latino que presentamos a continuación (...) Es el publicado por el P. Flórez» (J. GONZÁlEZ ECHEGARAY, A. DEL CAMPO HERNÁNDEZ y L. G. FREEMAN, Obras completas de Beato de Liébana, Madrid 1995, p. 29), razón por la cual no citan las lecturas divergentes en los códices conservados, señalando sólo «las variantes que contienen la edición de Sanders y la de Romero Pose en relación con la de nuestro autor, así como, a veces, las variantes según los autores que sirvieron de fuente al texto de Beato». Tampoco tomamos en consideración la edición de los mismos autores en Estudio del manuscrito del Apocalipsis de San Juan Beato de Liébana de San Miguel de Escalada, Valencia 2000, pp. 23-184 pues, como ellos mismos advierten, se trata del texto publicado cinco años antes —edición, advierten, «dirigida a un público no necesariamente especializado» - con algunas modificaciones (cf. Ibidem, p. 14).

$65 \mathrm{La}$ colación con nuestro texto sirve únicamente para realizar una primera aproximación, pues no todos los códices y fragmentos conocidos hasta la fecha fueron cotejados íntegramente por los citados editores. Las limitaciones de la edición de Sanders fueron ya puestas de relieve por M. C. DÍAZ Y DÍAZ, La tradición, p. 181. Señala H. A. Sanders con respecto al beato conservado en Manchester (sigla R): «sólo cotejé el prefacio y el libro I" (O.c., p. 237), con respecto al manuscrito $I$ : «sólo examiné unas pocas páginas suyas»(O.c., p.238), en referencia al volumen custodiado en Lisboa $(L)$ advierte: «por cotejar»(Ibidem) y, aludiendo al Beato Corsini indica: «no cotejado» (Ibidem), etc. Además, los criterios 
una veintena las lecturas significativas para nuestro objetivo ${ }^{66}$. Tomando como base el aparato crítico de E. Romero Pose son casi una treintena las variantes que pueden tenerse en cuenta ${ }^{67}$. Si conjugamos los resultados obtenidos a par-

a la hora de señalar variantes textuales dignas de mención reducen el campo de análisis Sirvan de ejemplo sus palabras: «En los [casos] de intercambio de $b$ y $v, d$ y $t, q u$ y $c, i$ e $y$, consonante doble o simple, he escrito siempre la forma correcta sin citar variantes» (H. A. SANDERS, Introducción: O.c., p.246). Similares criterios enuncia E. Romero Pose (Sancti Beati, pp.XII-XVI) quien, además, asume los datos relativos a seis códices aportados en la edición de Sanders: «Codicum lectiones, praeter eas quae ad codices Y, S, T, R, Cr, Vt pertinent, ex Sanders editione accepimus» (Ibidem, p. XVII).

En el aparato crítico que acompaña a los pasajes recogidos en los fragmentos objeto de estudio en la edición de H. A. Sanders aparecen los códices correspondientes a las siglas: A, C, E, F, G, H, M, N, P, Q, $\mathrm{S}, \mathrm{T}, \mathrm{U}, \mathrm{V}$ e Y. A estos se añaden en la edición de E. Romero Pose los signados como Cr, R y Vt. Para la identificación de los manuscritos correspondientes a las siglas $A, E, G, H, M, N, S, U, V$ e $Y$ véase el Cuadro 1. Los códices a los que pertenecen las restantes siglas, todos ellos más jóvenes que el zamorano, son los siguientes: C (París, Bibliothèque Nationale, ms. nouv. acq. lat. $2290+$ New York, coll. B. H. Breslauer [Beato de San Andrés de Arroyo]); F (Berlín, Staatsbibliothek, Ms. Theol. Lat. Fol.561 [Beato de Berlín]); $\mathrm{P}$ (Paris, Bibliothèque Nationale, ms. lat. 8878 [Beato de Saint-Sever]; Q (Paris, Bibliothèque Nationale, ms. nouv. acq. lat. 1366 [Beato de Navarra]); T (Turín, Biblioteca Nazionale, Ms. I-II-1 [Beato de Turín]); $\mathrm{Cr}$ (Roma, Biblioteca Corsiniana (Accademia dei Lincei), 369 (40.E.6) [Beato Corsini]); R (Manchester, John Rylands Library, ms. lat. 8 [Beato de Rylands]); Vt (Vaticano, Vat. Lat. 7621). Sobre el posible origen, datación etc., consúltense A. M. MUNDÓ y M. SÁNCHEZ MARIANA, Catalogación, pp. 102, 116, 119, 120, 121, 124, 126 y 127; E. ROMERO POSE, O.c., pp. VI-VIII y XVII y J. WILLIAMS, The illustrated beatus I, pp. 10-11 (excepto Vt).

Para abreviar las citas nos referiremos a los dos folios del A.H.P. de Zamora con la sigla Z.

${ }^{66}$ Son las siguientes (en la tercera columna figuran las siglas de los manuscritos con los que coincide la lectura), «Las cifras agregadas en igual forma [exponencial] a las iniciales representativas de los distintos manuscritos indican adiciones de segunda o tercera mano en sus textos»)(H. A. SANDERS, O.c., p.245).

\begin{tabular}{|c|c|c|c|c|c|}
\hline $\begin{array}{l}\text { Frag./col./reng. } \\
\text { Z 276r, a, } 11\end{array}$ & presenti & $\begin{array}{l}\text { coincidencia con: } \\
\mathrm{MA}^{2} \mathrm{TE}^{2} \mathrm{FPO}\end{array}$ & $\begin{array}{l}\text { Frag./col./reng. } \\
\mathrm{Z} 277 \mathrm{r}, \mathrm{a}, 2\end{array}$ & uestis & $\begin{array}{l}\text { coincidencia con: } \\
\text { YUMAGCSTV }\end{array}$ \\
\hline Z 276r, a, 11 & est om. & YUMAGC & $\mathrm{Z} 277 \mathrm{r}, \mathrm{a}, 7$ & quem & YUMGV \\
\hline $\mathrm{Z} 276 \mathrm{r}, \mathrm{a}, 19$ & tribuat & GCSTEFV & $\mathrm{Z} 277 \mathrm{r}, \mathrm{a}, 16$ & populum & $A^{1}$ \\
\hline $\mathrm{Z} 276 \mathrm{r}, \mathrm{b}, 17$ & pecodum & YGSEP $^{1}$ & Z 277r, a, 29 & idem & YUMA ${ }^{1} G C S E P^{1} V$ \\
\hline $\mathrm{Z} 276 \mathrm{r}, \mathrm{b}, 18$ & facit & YUMAGCSTV & $\mathrm{Z} 277 \mathrm{r}, \mathrm{b}, 2$ & Deus om. & YUMAGCSTV \\
\hline $\mathrm{Z} 276 \mathrm{r}, \mathrm{b}, 25$ & fructos & YGEVN & $\mathrm{Z} 277 \mathrm{r}, \mathrm{b}, 21$ & subleuet & $\mathrm{YUMA}^{1} \mathrm{GC}^{2} \mathrm{EP}^{1} \mathrm{VH}$ \\
\hline $\mathrm{Z} 276 \mathrm{v}, \mathrm{a}, 21$ & argumento & USFPNH & $\mathrm{Z} 277 \mathrm{r}, \mathrm{b}, 21$ & regio & YUMAGSV \\
\hline $\mathrm{Z} 276 \mathrm{v}, \mathrm{a}, 25$ & semper hoc $t r$ & A & $\mathrm{Z} 277 \mathrm{r}, \mathrm{b}, 22$ & seruat & $\mathrm{YUMA}^{1} \mathrm{GP}^{1} \mathrm{VH}$ \\
\hline $\mathrm{Z} 276 \mathrm{v}, \mathrm{b}, 9$ & de quod & $\mathrm{UAGV}^{2}$ & $\mathrm{Z} 277 \mathrm{r}, \mathrm{b}, 30$ & odorem & YUMA $^{1}$ GSEP $^{1} \mathrm{~V}$ \\
\hline $\mathrm{Z} 276 \mathrm{v}, \mathrm{b}, 24$ & uota & $\mathrm{Y}^{1} \mathrm{~A}^{1} \mathrm{CV}$ & Z $277 v, b, 29$ & storia & YA'S \\
\hline
\end{tabular}

${ }^{67}$ Las siguientes (la abreviatura.codd. engloba la totalidad de los códices cotejados y cet. (ceteri codices) los manuscritos colacionados excepto los que corresponden a las siglas situadas entre corchetes):

Z: Frag./col./reng.

276r, a, 18

276r, a, 19

276r, b, 12

276r, b, 17

276r, b, 18

276v, a, 19

$\begin{array}{ll} & \text { coincidencia con: } \\ \text { alterius } & \text { cet. [excepto VA }{ }^{2} \mathrm{HFQVTY} \text { ] } \\ \text { tribuat } & \text { SVGTCEF } \\ \text { regioni } & \text { cet. [excepto } \mathrm{U}^{2} \text { TPAGC] } \\ \text { illa } & \text { cet. [excepto UA } \mathrm{U}^{2} \text { TPFQ] } \\ \text { facit } & \text { YSVUMAGT } \\ \text { augmento } & \text { codd. }\end{array}$

Textos medievales

Hispania Sacra 55 (2003) 
tir de ambas colaciones, los manuscritos textualmente más emparentados con Z son Y, G, U, V, M y S. Es decir, los beatos de Escalada, Gerona, Urgel, Valcavado, Fernando I y Silos, todos ellos visigóticos ${ }^{68}$. Un repaso a las discrepancias entre $\mathrm{Z}$ y los volúmenes citados nos permitiría ordenar los ejemplares - de mayor a menor parentesco con Z- de este modo: Y, S, U, M, V y G.

Fijado un punto de arranque partiendo de las dos ediciones citadas, intentaremos un paso más. Para ello, es necesario realizar un cotejo del texto superviviente de los fragmentos zamoranos $(\mathrm{Z})$ con el que transmiten los doce beatos enteramente visigóticos que cuentan en todo o en parte con los pasajes objeto de interés. En el siguiente cuadro indicamos los manuscritos o fragmentos de manuscritos considerados, la sigla utilizada ${ }^{69}$ (con una $c$ exponencial añadida a

\begin{tabular}{|c|c|c|}
\hline $276 \mathrm{v}, \mathrm{a}, 21$ & argumento & SUNPHF \\
\hline $276 v, a, 25$ & semper hoc & A \\
\hline $276 v, b, 9$ & de quod & $Y^{1}$ \\
\hline $276 \mathrm{v}, \mathrm{b}, 12-13$ & conecti & cet. $[$ excepto T] \\
\hline $276 \mathrm{v}, \mathrm{b}, 13$ & claritatis & YSTCrVt \\
\hline $276 v, b, 24$ & uota & $\mathrm{Y}^{1} \mathrm{VA}^{1} \mathrm{C}$ \\
\hline $276 \mathrm{v}, \mathrm{b}, 26$ & excedet & cet. [excepto $\mathrm{MA}^{2} \mathrm{TCP}^{2} \mathrm{HFQ}$ ] \\
\hline $277 \mathrm{r}, \mathrm{a}, 2$ & uestis & YSVUMAGTC \\
\hline $277 \mathrm{r}, \mathrm{a}, 7$ & quem & YVUMG \\
\hline $277 r, a, 16$ & populum & $A^{1}$ \\
\hline $277 \mathrm{r}, \mathrm{a}, 17-18$ & auditu & codd. \\
\hline $277 r, a, 29$ & idem & YSVUMA $^{1} \mathrm{GCP}^{1} \mathrm{E}$ \\
\hline $277 \mathrm{r}, \mathrm{b}, 2$ & Deus om. & YSVUMAGTC \\
\hline $277 \mathrm{r}, \mathrm{b}, 9$ & quid & cet. [excepto NPQVt] \\
\hline $277 \mathrm{r}, \mathrm{b}, 16$ & uita om. & cet. [excepto QVt] \\
\hline $277 \mathrm{r}, \mathrm{b}, 21$ & subleuet & YVUMA ${ }^{1} \mathrm{GC}^{2} \mathrm{P}^{1} \mathrm{EH}$ \\
\hline $277 \mathrm{r}, \mathrm{b}, 21$ & regio & YSVUMAG \\
\hline 277 r, b, 22 & seruat & YVUMA ${ }^{1} \mathrm{GP}^{1} \mathrm{H}$ \\
\hline $277 \mathrm{r}, \mathrm{b}, 30$ & odorem & YSVUMA $^{1} \mathrm{GP}^{1} \mathrm{E}$ \\
\hline $277 \mathrm{v}, \mathrm{a}, 4$ & isdem & cet. [excepto TQ] \\
\hline $277 \mathrm{v}, \mathrm{a}, 12-13$ & ineffusionem & cet. [excepto GEFQVtNP] \\
\hline
\end{tabular}

68 ¿Con qué manuscritos presenta $\mathrm{Z}$ mayor número de coincidencias? Los resultados tras el cotejo con la edición de Sanders no dejan lugar a dudas: el texto de los fragmentos se acercaría especialmente al de los códices G, Y, U, V, M y S. Se situarían a cierta distancia el texto originario de A y $\mathrm{C}$, si bien modificaciones posteriores en el primer manuscrito lo aproximarían sensiblemente a $\mathrm{Z}$, y el escurialense $\mathrm{E}$. Aún menor número de semejanzas se advierten con $\mathrm{T}, \mathrm{F}$ y $\mathrm{H}$-coincidencias siempre compartidas con la mayor parte de los códices cotejados- y los contactos con el texto originario de $\mathrm{P}$ y, especialmente, con $\mathrm{N}$ y $\mathrm{Q}$ serían prácticamente inexistentes.

La confrontación entre el texto de $\mathrm{Z}$ y el editado por Romero Pose proporciona similares resultados. Serían numerosas las relaciones -explícitas o implícitas (nos referimos a las recogidas con las abreviaturas codd. y cet.) - con V, Y, G, S, U y M. A continuación, atendiendo a las similitudes, se situarían los códices $\mathrm{A}, \mathrm{C}, \mathrm{E}, \mathrm{T}$ y $\mathrm{H}$. Por último, con pocas concordancias e irrelevantes, los ejemplares $\mathrm{F}, \mathrm{Cr}, \mathrm{Vt}, \mathrm{Q}, \mathrm{P}$ y $\mathrm{N}$.

${ }^{69}$ Con el fin de facilitar la identificación de los ejemplares, emplearemos las siglas de la edición realizada por E. Romero-Pose, excepto en la correspondiente para designar los fragmentos de Silos (nos 
la sigla indicaremos modificaciones en el texto debida a correctores y lectores $^{70}$ ) y los folios (especificando recto o vuelto), columna $(\mathrm{a}, \mathrm{b})$ y renglón de la columna en el que se localiza el texto ${ }^{71}$.

\section{CUADRO 2}

\begin{tabular}{|l|c|l|l|}
\hline Zamora, AHP & Z & fragmento 276 & fragmento 277 \\
\hline Burgo de Osma, Catedral, Cod.1 & O & f.78v,a,10-f.79r,a,13 & f.80r,a,23-f.80v,a,29 \\
\hline $\begin{array}{l}\text { Escorial, Biblioteca del monasterio, } \\
\text { \& II.5 }\end{array}$ & E & f.66r,b,3-f.67r,a,2 & f.68v,a,14-f.69r,b,17 \\
\hline Gerona, Catedral, ms. 7 & G & f.116r,a,30-f.117r,a,3 & f.118v,a,20-f.119r,b,2 \\
\hline $\begin{array}{l}\text { Londres, British Library, Add. Ms. } \\
\text { 11695 }\end{array}$ & S & f.93r,a,13-f.93v,b,12 & f.95r,b,14-f.96r,a,14 \\
\hline $\begin{array}{l}\text { Madrid, Academia de la Historia, } \\
\text { Códice 33 }\end{array}$ & H & f.99v,b,14-f.100v,b,8 & f.102v,b,1-f.103v,a,21 \\
\hline $\begin{array}{l}\text { Madrid, Archivo Histórico Nacional, } \\
\text { Cod.1097 (Vit.35, n.257; 1240B) }\end{array}$ & A & f.71v,b,20-f.72v,a,29 & f.74r,a,34-f.75r,a,1 \\
\hline $\begin{array}{l}\text { Madrid, Biblioteca Nacional, ms. } \\
\text { Vitr.14-1 }\end{array}$ & N & f.64r,b,9-f.65r,a,3372 & f.67r,a,32-f.68r,a,25 \\
\hline $\begin{array}{l}\text { Madrid, Biblioteca Nacional, ms. } \\
\text { Vitr.14-2 }\end{array}$ & M & $\begin{array}{l}\text { f.123v,b,34- } \\
\text { f.124v,b,15 }\end{array}$ & $\begin{array}{l}\text { f.126v,a,15- } \\
\text { f.127r,b,29 }\end{array}$ \\
\hline $\begin{array}{l}\text { New York, Pierpont Morgan Libra- } \\
\text { ry, ms.644 }\end{array}$ & Y & f.94v,b,14-f.95v,b,4 & f.97v,a,9-f.98r,b,27 \\
\hline Seo de Urgel, Catedral, códice 4 & U & f.94v,a,34-f.95r,b,25 & f.96v,b,4-f.97r,b,29 \\
\hline $\begin{array}{l}\text { Silos, Biblioteca del Monasterio, } \\
\text { fragmento 373 }\end{array}$ & F & $\begin{array}{l}\text { frag.3r,a,[1]- } \\
\text { frag.3r,b,[18] }\end{array}$ & - \\
\hline $\begin{array}{l}\text { Valladolid, Biblioteca de la Univer- } \\
\text { sidad, ms. 43374 }\end{array}$ & V & f.84r,b,6-f.84v,b,26 & f.86r,a,36-f.86v,b,20 \\
\hline
\end{tabular}

serviremos de la letra F, propuesta por Neuss). La correspondencia entre las siglas de Sanders/ Romero Pose y las de Neuss (asumidas por investigadores como Klein y Williams) puede verse en el Cuadro 1.

70 Entendemos que es interesante reflejar cuáles eran los vocablos originarios para establecer la filiación de los ejemplares. Son especialmente relevantes las modificaciones en los códices Vitr.14-1, Escorial, San Millán y, sobre todo, Tábara.

71 Advertimos que sólo hemos podido llevar a cabo la colación con cuatro originales (A, F, H y N). El resto de los manuscritos los hemos consultado a partir de facsímiles.

72 Tenemos en cuenta la foliación más reciente, a lápiz, dispuesta en el ángulo superior derecho del recto de los folios y no citamos la anterior, a tinta, situada en el margen superior de las mismas páginas.

${ }^{73}$ Debido a la mutilación del folio sólo es posible un cotejo con Z 276r, b, 31- Z 276v, a, 30 y Z 276v, b, 10- Z 276v, b, 31.

${ }^{74} \mathrm{La}$ colación ha presentado notables problemas Es bastante frecuente a lo largo del volumen que la tinta del recto del folio sea visible al vuelto y viceversa, con lo que la lectura se complica, y más si, como es nuestro caso, ha de acudirse al facsímil del libro. Este hecho se advierte en la segunda

Textos medievales

Hispania Sacra 55 (2003) 
Las relaciones existentes entre los manuscritos recogidos en el cuadro anterior han sido objeto de atención de los investigadores como aspecto esencial para dibujar el árbol genealógico de los beatos. Conviene que conozcamos, siguiera someramente, algunas de las propuestas al respecto ${ }^{75}$.

Para H. A. Sanders ${ }^{76}$, los manuscritos correspondientes a las siglas Y, S, V, $\mathrm{U}, \mathrm{M}$ constituyen la que denomina «primera clase» ${ }^{77}$. En su opinión «transcriben la tercera versión de Beato, la de 786, en su forma pura, aunque los respectivos copistas sucumbieron en ocasiones al influjo de otros tipos de texto ${ }^{78}$. Las relaciones entre los componentes de esta familia son complejas ${ }^{79}$. A la «segunda clase», conformada por ocho beatos, pertenecen A y G ${ }^{80}$. Los manuscritos de esta clase «muestran una revisión diferenciada del texto de la tercera versión, contaminada por la segunda» ${ }^{81}$. En la que considera «tercera clase» se insertan, junto a otros cuatro, los códices $\mathrm{N}, \mathrm{H}, \mathrm{E}$ y $\mathrm{O}^{82}$. De acuerdo, pues, a los criterios de Sanders, los ejemplares recogidos en el Cuadro 2 se dividirían en tres grupos ${ }^{83}$ :

columna del f.86v del beato de Valcavado y no descartamos, por ello, que alguna variante comprendida en el texto $Z 277 \mathrm{v}$, b, 4-31 haya podido pasar desapercibida ante nuestros ojos.

75 Traducimos las siglas de los diversos autores a las propuestas por Sanders.

76 No tiene en cuenta el fragmento que designamos con la sigla $F$ pues, como advierte explícitamente, «Hay otro fragmento de tres folios en Santo Domingo de Silos que no he podido examinar» (H. A. SANDERS, O.c., p. 241).

77 Ibidem, pp. 236-237. Grupo de beatos que se caracterizan porque contienen «el capítulo De Antichristo, tomado en su mayor parte del De civitate Dei $(20,19)$ agustiniano» inserto "como capítulo 7 del libro XI» (Ibidem, p. 239).

78 Ibidem, p. 241.

79 Considera Sanders que «el mejor y más antiguo es $Y$ », que «de un mismo original se derivan probablemente Y y S», «los ejemplares U y V muestran también parentesco», «entre V y V se observan igualmente coincidencias, aunque menos marcadas», «el códice $\mathrm{M}$ parece más próximo a Y», etc. (Ibidem, p. 241).

80 Ibidem, p. 237. Precisamente serían los dos citados «los ejemplares mejores y más antiguos» (Ibidem, p.242).

81 Ibidem, p. 242.

82 Cf. Ibidem, pp. 238-239. Son ejemplares que carecerían del citado capítulo De Antichristo (Ibidem, p. 239). El ejemplar N junto a un manuscrito posterior (P) correspondería a «la versión primaria» pero mostrando «una revisión textual divergente de la del resto de los códices» (Ibidem, $\mathrm{p}$. 239). El Beato Vitr. 14-1 es, para este investigador, «una copia mucho más fiel del manuscrito original» que los restantes de su clase (Ibidem, p. 240).

83 Otros investigadores que se han ocupado del tema coinciden con esta propuesta divisoria, al menos en lo que afecta a los manuscritos visigóticos que nos ocupan. Así, de acuerdo al estudio del prefacio de la obra que realizó M. A. Beloira Bértolo, se pueden dividir los manuscritos que nos interesan en tres familias. La que denomina «familia $\alpha$ » incluye los ejemplares M, S, U, V, Y. A la «familia $\beta$ » pertenecen A y G a la «familia $y$ » corresponden E, H, N, O (cf. M. A. BELOIRA BÉRTOLO, Beato de Liébana. Comentario al Apocalipsis. Prefacio (Texto, traducción y notas): Archivos Leoneses 91-92(1992)301). 


\section{CUADRO 3}

\begin{tabular}{|c|c|c|}
\hline Primera ClaSe & Segunda ClASE & Tercera ClaSe \\
\hline M S U V Y & A G & E H N O \\
\hline
\end{tabular}

En el stemma de la tradición - textual y pictórica- propuesto por W. Neuss, los beatos se dividen en dos ramas principales (I y II $)^{84}$. A diferencia de Sanders, no admite la existencia de varias redacciones de la obra y considera que ambas ramas derivan de un mismo exemplar. Teniendo el cuenta como criterio esencial la iluminación, la rama II se bifurcaría en dos líneas secundarias (IIa y IIb). Los manuscritos que nos interesan se distribuyen del siguiente modo:

\section{CUADRO 4}

\begin{tabular}{|c|c|c|}
\hline RAMA I & \multicolumn{2}{|c|}{ RAMA II } \\
\hline E HNO & IIa & IIb \\
& M S U V Y & A F G \\
\hline
\end{tabular}

P. K. Klein ha dibujado el árbol genealógico en más de una ocasión. En el pormenorizado estudio del Beato Vitr.14-1, publicado en 1976, traza dos stemmata, uno de tradición textual y otro de tradición pictórica ${ }^{85}$. En su reflexión sobre la tradición textual ${ }^{86}$ admite Klein la existencia de tres redacciones de la obra propiamente dichas y una revisión de la tercera redacción ${ }^{87}$. Los beatos que nos ocupan se dividirían asi ${ }^{88}$ :

84 Cf. W. NEUSS, O.c., p. 111.

${ }^{85}$ Cf. P. K. KLEIN, Der ältere Beatus-Kodex Vitr.14-1, II, pp. 655-656. Los mismos diagramas se reproducen en un trabajo posterior: La tradición pictórica de los beatos: Actas del Simposio para el estudio de los códices del «Comentario al Apocalipsis» de Beato de Liébana, II, Madrid 1980, pp. 87 y 96. Como señala este investigador, citando a $\mathrm{K}$. Weitzmann, «es absolutamente indispensable investigar separadamente la tradición textual y la tradición pictórica» (Ibidem, p. 88). En un reciente trabajo vuelve a ocuparse de la cuestión y, en concreto, se centra en redibujar las relaciones existentes entre los ejemplares que presentan la «versión» pictórica «reciente» (cf. P.K. KLEIN, Beatus de Liébana. Codex Urgellensis, p. 41).

${ }^{86}$ No nos detendremos en sus observaciones sobre la tradición pictórica ya que los fragmentos del A.H.P. zamorano carecen de iluminación. Señalemos únicamente que los ejemplares E, H (parte «mozárabe») y $\mathrm{N}$ pertenecerían a la primera versión pictórica y los restantes manuscritos a la «segunda versión pictórica».

87 «En cuanto a la tradición textual, la teoría de Sanders acerca de las diferentes redacciones parece la más convincente» (P. K. KLEIN, La tradición pictórica, p. 86).

${ }^{88} \mathrm{Al}$ igual que en los casos anteriores, adaptamos las siglas.

Textos medievales

Hispania Sacra 55 (2003) 


\section{CUADRO 5}

\begin{tabular}{|c|c|c|c|}
\hline $\begin{array}{c}\text { PRIMERA REDACCIÓN } \\
\text { (A. 776) }\end{array}$ & $\begin{array}{c}\text { SEGUNDA REDACCIÓN } \\
\text { (A. 784) }\end{array}$ & \multicolumn{2}{|c|}{ TERCERA REDACCIÓN } \\
\hline $\mathrm{N}$ & E H O & M S U V Y & $\begin{array}{c}\text { tercera redacción revisada } \\
\text { A F G }\end{array}$ \\
\hline
\end{tabular}

La aproximación que lleva a cabo M. C. Díaz y Díaz introduce el criterio geográfico en el análisis. Un primer grupo de ejemplares - «el modelo de este grupo representa la más antigua rama de la tradición de los Beatos»- estaría formado por $\mathrm{E}, \mathrm{H}$ y $\mathrm{N}$ y, «en conexión más ligera con ellos, pero siempre dentro de la misma línea textual», el manuscrito $\mathrm{O}^{89}$. Un segundo grupo «es el que podríamos llamar leonés, por la zona donde fueron realizadas las diferentes copias $\rangle^{90}$.

En su stemma, J. W. Williams sólo introduce los ejemplares iluminados. En todo caso, la distribución de los manuscritos en la ramas I y II coincide en lo sustancial con las anteriores propuestas, pues los testigos A G M S U V Y no pertenecen a la rama $\mathrm{I}^{91}$.

Como vemos, no existe total acuerdo entre los expertos, pero, aún así, sí se advierte un «máximo común denominador» en las propuestas: la existencia de dos grupos claros, aunque, evidentemente, relacionados entre sí y contaminados, uno constituido por los ejemplares $\mathrm{E} \mathrm{H} \mathrm{N} \mathrm{O} \mathrm{y} \mathrm{otro} \mathrm{formado} \mathrm{por} \mathrm{los} \mathrm{beatos} \mathrm{A} \mathrm{F}$ G M S U V Y ¿A qué grupo pertenecen los dos folios del A.H.P. de Zamora?

El resultado de la colación entre el texto de los fragmentos zamoranos y el de los doce ejemplares visigóticos anteriormente citados puede verse en el Apéndice, apartado 6 de este trabajo. Operando con más de cuatrocientas lecturas $^{92}$ y estableciendo las oportunas relaciones entre los manuscritos obtenemos las siguientes conclusiones:

89 Junto al fragmento 1 del monasterio de San Pedro de las Dueñas (M. C. DíAZ y DíAZ, La tradición, p. 176).

90 Ibidem, p. 177.

${ }^{91}$ Sin embargo, difiere con respecto a los diagramas de Neuss y Klein las relaciones que se establecen entre los manuscritos y, en concreto, la división entre las ramas IIa y IIb. No considera este autor que las citadas IIa y IIb sean resultado de una bifurcación de la rama II verificada en un mismo punto de la tradición (Neuss). J.W. Williams hace partir de la rama IIa cuatro líneas secundarias: en la primera se sitúa Y, la segunda es la citada rama IIb (constituida entre otros por los ejemplares A y G), la tercera recoge los manuscritos U V M y en la cuarta se dispone S (cf. J. W. WILLIAMS, The illustrated Beatus I, p. 26).

92 Hemos considerado todas las variantes posibles (adiciones, omisiones, transposiciones, términos distintos, variaciones de número y caso, e caudata/e simple, alternancia $e / i, i / y$, fluctuaciones entre $m$ y $n, d / t$ en posición final de sílaba, geminaciones, $h$ inicial, $p h$ por $f$, etc.), aunque, como seña- 
$1^{\circ}$.- En el estado actual de los fragmentos, sólo podríamos señalar una variante exclusiva de $\mathrm{Z}$, la siguiente omisión:

Z 276r,a,11 molestiam: molestiam que AGHMOSUV molestiam que EN

Sin embargo, esta omisión actual no nos sirve para establecer la filiación del manuscrito, pues tras molestiam se percibe una raspadura que bien podría ocultar ahora a nuestros ojos la abreviatura $q^{s}$.

$2^{\circ}$.- El beato $Z$ no pertenece al grupo de manuscritos considerados por Sanders «de la tercera clase», por Neuss de la rama I, por Klein de las dos primeras redacciones - y de la "primera vesión pictórica»—y por Díaz y Díaz representantes «de la más antigua redacción de la obra». Nos referimos a los ejemplares E, H, N, O es decir, los beatos de El Escorial, San Millán, Vitr.14$1 \mathrm{y} O s m a^{94}$. En efecto, son estos cuatro ejemplares los que mayor número de divergencias importantes presentan con respecto a los fragmentos del A.H.P. de Zamora. No obstante, hemos de señalar que, pese a ello, las discrepancias entre $\mathrm{Z}$ y $\mathrm{H}$-el más distanciado - no alcanzan siquiera a la tercera parte de los aproximadamente cuatrocientos casos tomados en consideración ${ }^{95}$. Este hecho puede tener estrecha relación con la temprana fecha que atribuimos a las piezas zamoranas $\mathrm{y}$, por supuesto, con las numerosas contaminaciones advertidas, que podrían derivarse del lugar en el que vio la luz $\mathrm{Z}$.

$3^{\circ}$.- Como consecuencia de lo anteriormente señalado, el beato del A.H.P. de Zamora se insertaría en las familias primera o segunda de Sanders, en la rama II del stemma diseñado por Neuss - ¿IIa? ¿IIlb?-, en la tercera redacción textual según Klein (¿tercera redacción propiamente dicha o tercera redacción revi-

\footnotetext{
la J. A. FERNÁNDEZ FLÓREZ, Fragmentos, p.414: «Es claro que no marca igualmente las diferencias con otro texto el hecho de que uno utilice una $e$ caudada o no; o bien, que en un determinado momento una palabra acabe en $u$ o en $m$; y ello, por existir otro tipo de variantes tales como palabras o frases completas, totalmente nuevas, distintas u omitidas, según los diferentes códices».

93 Nos referimos obviamente a los doce ejemplares visigóticos, pues un manuscrito pregótico Paris, Bibliothèque Nationale, Nouv. acq. lat. 2290 (Beato de San Andrés de Arroyo), muy ligado al grupo A, F, G. presenta la misma omisión en el f. 62r, a, 4. Entendemos que esta peculiar coincidencia entre $\mathrm{Z}$ y el Beato de San Andrés de Arroyo aporta un dato importante para ubicar este segundo ejemplar en el stemma de los beatos.

94 No discutimos la cohesión del grupo, pero sí constatamos algunas lecturas que evidencian oposición entre $\mathrm{O}$ y los tres ejemplares restantes. Además, es el Beato de Osma el único de los cotejados en el que se encuentra una glosa marginal asociada al texto que nos ocupa. En el margen de canal del f.80v, a la altura del renglón 28 de la 10 columna, leemos en escritura visigótica probablemente de la misma mano que el texto base o semejante, pero de menor módulo, la siguiente explicación enmarcada: Ubi dominus noster candelabrum significat.

95 Para entender nuestra afirmación puede tenerse en cuenta la tabla de concordancias y discrepancias que recoge J. A. FERNÁNDEZ FLóREZ, Fragmentos, p.415.
}

Textos medievales

Hispania Sacra 55 (2003) 
sada?) y en el grupo de «manuscritos leoneses» para Díaz y Díaz ${ }^{96}$. Teniendo en cuenta el estudio de la forma y la datación que atribuimos a las piezas zamoranas, el beato $Z$ es más antiguo que los ocho ejemplares que se asocian a las siglas A F G M S U V Y ${ }^{97}$; por lo tanto, el primero de los testigos supervivientes de las clases primera y segunda de Sanders, de la «rama II» de Neuss y de la «tercera redacción» según Klein.

$4^{\circ}$.- Partiendo de las divergencias significativas, y teniendo en cuenta su proximidad al texto de $Z$, pueden ordenarse los manuscritos del siguiente mo$\mathrm{do}^{98}$ : los códices $\mathrm{A}$ e $\mathrm{Y}$ en primer lugar, seguidos de $\mathrm{S}, \mathrm{M}, \mathrm{U}-\mathrm{V}^{99} \mathrm{y}$, a cierta distancia, $\mathrm{G}$, con numerosas variantes exclusivas debidas en buena parte a una deficiente interpretación de su modelo.

$5^{\circ}$.- Hemos situado en primer lugar, conjuntamente, los beatos de Escalada (Y) y Tábara. (A). Si tomamos en consideración el texto originario de ambos ejemplares ${ }^{100}$, hallamos que $\mathrm{Z}$ prácticamente equidista —en lo que se refiere al

96 Veamos algunos ejemplos que muestran claramente la oposición de $\mathrm{Z}$ al grupo $\mathrm{E} \mathrm{H} \mathrm{N} \mathrm{O}$ y su adscripción al otro conjunto de ejemplares:

\begin{tabular}{|c|c|c|c|}
\hline $276 \mathrm{r}, \mathrm{a}, 7$ & $\begin{array}{l}\mathrm{Z} \\
\text { egritudinem }\end{array}$ & $\begin{array}{l}\text { EHNO } \\
\text { egritudine }\end{array}$ & $\begin{array}{l}\text { AGMSUVY } \\
\text { egritudinem }\end{array}$ \\
\hline $276 \mathrm{r}, \mathrm{b}, 7$ & Hecc & hoc & Hecc / Hec (A G) \\
\hline $276 \mathrm{r}, \mathrm{b}, 18$ & facit & faciat & facit \\
\hline $276 \mathrm{r}, \mathrm{b}, 29$ & in & om. & in \\
\hline $276 \mathrm{v}, \mathrm{a}, 8$ & Deus & om. & Deus \\
\hline $276 \mathrm{v}, \mathrm{a}, 8$ & ad hoc & adhuc & ad hoc \\
\hline $276 v, a, 11$ & ad hoc & adhuc & ad hoc \\
\hline $276 v, a, 24$ & bona & bono & bona \\
\hline $276 v, a, 26$ & quid & quod & quid \\
\hline $277 \mathrm{r}, \mathrm{a}, 2$ & uestis & uestimentis & uestis \\
\hline $277 \mathrm{r}, \mathrm{b}, 18$ & quia & qui & quia \\
\hline
\end{tabular}

Para perfilar la posición de Z en la familia II son interesantes las dos lecturas siguientes:

$\begin{array}{llllll} & \text { Z } & \text { MUVY } & \text { AG } & \text { S } & \text { EHNO } \\ 276 \mathrm{v}, \mathrm{a}, 24 & \text { debuerunt } & \text { om. } & \text { debuerunt } & \text { debuerunt } & \text { debuerunt } \\ 277 \mathrm{r}, \mathrm{a}, 22 & \text { per } & \text { om. } & \text { per } & \text { per } & \text { per }\end{array}$

$97 \mathrm{La}$ aproximación realizada a partir de la forma nos llevaba a concluir que sólo dos de los ejemplares visigóticos citados podrían considerarse anteriores al zamorano (fragmento 4 de Silos y fragmento 1 de San Pedro de las Dueñas) y un códice —el Beato Vitr.14-1 - coetáneo. Todos ellos se hallarían en la rama I. Véase la posición del fragmento silense y del manuscrito de la Biblioteca Nacional en el stemma de W. NEUSS, O.c., p. 111. Por lo que se refiere al folio leonés, señala M.C. Díaz y Díaz: «nos encontramos con un texto muy emparentado con Madrid, Academia de la Historia, Emilianense 33, y algunos otros» (Un nuevo fragmento, p. 17).

98 Prescindimos de $\mathrm{F}$ en esta valoración, pues sólo es posible cotejar una pequeña parte del texto.

99 Los situamos conjuntamente debido al especial parentesco que observamos en el texo. La estrecha relación entre Urgel y Valcavado, teniendo en cuenta la iluminación, es destacada por P.K. KLEIN, Beatus de Liébana. Codex Urgellensis, p. 24.

100 Es decir, antes de que se verificasen en estos dos conocidísimos beatos modificaciones y adiciones realizadas por manos posteriores. 
número de disimilitudes relevantes- de estos dos manuscritos. Entendemos que esta referencia al estado original de los textos en ambos volúmenes es esencial para filiarlos con mayor seguridad. Así, a modo de ejemplo, una adición en grafía tardía subsana en $\mathrm{Y}$ la omisión de debuerunt ${ }^{101}$, omisión común a otros tres códices de la misma familia $(\mathrm{M}, \mathrm{U} \text { y V })^{102}$. En el caso del beato tabarense (A) proliferan las intervenciones que alteraron el texto inicial ${ }^{103} \mathrm{y}$ que lo alejan tanto del reproducido en $\mathrm{Z}^{104}$ como del presente en otros volúmenes estrechamente relacionados con él, como es el caso del Beato de Gerona $(G)$ o el tercer fragmento silense $(F)$.

En torno a medio centenar de disimilitudes pueden observarse entre $\mathrm{Z}$ e $\mathrm{Y}$, pero la mayoría responde únicamente a la adopción de $e$ simple frente a la $e$ caudada y, secundariamente, a la presencia o no de $h$ inicial y a la oscilación

${ }^{101} \mathrm{Z} 276 \mathrm{v}, \mathrm{a}, 24$.

102 Esta omisión en M U V Y y no en el silense nos permite llamar la atención sobre la particular posición de $\mathrm{S}$ en este grupo. El Beato de Silos, no participa de algunas peculiaridades comunes a A G M U V Y y se sitúa en éstas junto a los componentes de la rama I:

\begin{tabular}{lllll}
\multicolumn{1}{c}{ Z } & S & EHNO & MUVY & AG \\
276r, a, 11 presenti & est add. & est add. & - & - \\
276v, a, 1 substernunt & substernant & substernant & substernunt & substernunt \\
276v, a, 24 debuerunt & debuerunt & debuerunt & om. & debuerunt \\
276v, b, 9 de & dixit & dixit & de & de \\
276v, b, 24 uota & uita & uita & uota & uota \\
277r, a, 22 per & per & per & om. & per
\end{tabular}

103 Nos referimos a las acciones que, claramente, modificaron términos. Otras intervenciones, también numerosas, parece ser que sólo tuvieron por objeto repasar, con tinta más oscura, caracteres gráficos semiborrados o difícilmente legibles.

${ }^{104}$ Creemos que la siguiente relación es suficientemente explícita:

$\begin{array}{llll} & \text { Z } & \text { Tábara orig. }(A) & \text { Tábara final }\left(\mathrm{A}^{\mathrm{c}}\right) \\ 276 \mathrm{r}, \mathrm{a}, 3 & \text { istis } & \text { istis } & \text { isti } \\ 276 \mathrm{r}, \mathrm{a}, 18 & \text { alterius } & \text { alterius } & \text { alter } \\ 276 \mathrm{r}, \mathrm{b}, 17 & \text { pecodum } & \text { pecodum } & \text { pecudum } \\ 276 \mathrm{r}, \mathrm{b}, 17 & \text { illa } & \text { Illa } & \text { illam } \\ 276 \mathrm{v}, \mathrm{a}, 11 & \text { pertraunt } & \text { pertraunt } & \text { pertra }<\mathrm{h}>\text { unt } \\ 276 \mathrm{v}, \mathrm{a}, 21 & \text { argumento } & \text { argumento } & \text { argumentu } \\ 276 \mathrm{v}, \mathrm{b}, 20 & \text { laboriosior } & \text { laboriosior } & \text { laboriosius } \\ 277 \mathrm{r}, \mathrm{a}, 16 & \text { populum } & \text { populum } & \text { populus } \\ 277 \mathrm{r}, \mathrm{a}, 31 & \text { benedictionem } & \text { benedictionem } & \text { benedictione } \\ 277 \mathrm{r}, \mathrm{b}, 11 & \text { suabe } & \text { suabe } & \text { suaue } \\ 277 \mathrm{r}, \mathrm{b}, 12 & \text { refobet } & \text { refobet } & \text { refouet } \\ 277 \mathrm{r}, \mathrm{b}, 21 & \text { subleuet } & \text { subleuet } & \text { subleuent } \\ 277 \mathrm{r}, \mathrm{b}, 22 & \text { seruat } & \text { seruat } & \text { seruant } \\ 277 \mathrm{r}, \mathrm{b}, 30 & \text { odorem } & \text { odorem } & \text { odore } \\ 277 \mathrm{v}, \mathrm{b}, 17 & \text { traitur } & \text { traitur } & \text { tra }<\mathrm{h}>\text { itur } \\ 277 \mathrm{v}, \mathrm{b}, 23 & \text { uidebatur } & \text { uideatur } & \text { uide }<\mathrm{b}>\mathrm{atur} \\ 277 \mathrm{v}, \mathrm{b}, 28 & \text { sciffos } & \text { sciffos } & \text { scifos }\end{array}$

Textos medievales

Hispania Sacra 55 (2003) 
$u / b$. Fuera de éstas, sólo observamos discrepancias en las siguientes lecturas, variantes que citamos especificando los manuscritos con los que coincide $\mathrm{Y}$ :

\begin{tabular}{|c|c|c|c|}
\hline & $\mathrm{Z}$ & $\mathrm{Y}$ & \\
\hline $276 r, a, 11$ & molestiam $\left(Z^{\mathrm{c}}\right)^{105}$ & molestiam que & (= AEGHMNOSUV) \\
\hline $276 r, a, 11$ & presenti $\left(Z^{\mathrm{c}}\right)$ & presentis & (= AGHMNSUV) \\
\hline $276 \mathrm{r}, \mathrm{b}, 2$ & tangunt & tagvunt & \\
\hline $276 r, b, 17$ & ubertate & hubertate & (= AGMSUVY) \\
\hline $276 r, b, 18$ & quum & cum & $(=\mathrm{HMNU})$ \\
\hline $276 \mathrm{r}, \mathrm{b}, 25-26$ & impendunt & inpendunt & (= EHMSUV) \\
\hline $276 \mathrm{v}, \mathrm{a}, 24$ & debuerunt & om. & $(=$ MUV) \\
\hline $276 \mathrm{v}, \mathrm{a}, 25$ & semper hoc $\left(Z^{c}\right)$ & hoc semper & (= EHMNOSUV) \\
\hline $276 v, b, 8$ & occulis & oculis & (= AHMNOSUV) \\
\hline $277 \mathrm{r}, \mathrm{a}, 10$ & Iudaicus & Iudaycus & $(=\mathrm{AGMNOUV})$ \\
\hline $277 \mathrm{r}, \mathrm{a}, 13$ & Isaac & Ysaac & (= AEGHNSUV) \\
\hline $277 r, a, 17$ & mici & mihi & (= MUV) \\
\hline $277 \mathrm{r}, \mathrm{a}, 22$ & per & om. & $(=\mathrm{MUV})$ \\
\hline $277 \mathrm{r}, \mathrm{b}, 23$ & cum & quum & (= EHMOSU) \\
\hline $277 \mathrm{v}, \mathrm{a}, 19$ & Iudaicus & Iudaycus & $(=\mathrm{AGHMNU})$ \\
\hline $277 \mathrm{v}, \mathrm{b}, 10$ & Idrias & Ydrias & $(=\mathrm{HU})$ \\
\hline $277 \mathrm{v}, \mathrm{b}, 28$ & sciffos & scifos & (= EGHMNOSU) \\
\hline $277 \mathrm{v}, \mathrm{b}, 28$ & ac & hac & $(=\mathrm{AGUV})$ \\
\hline
\end{tabular}

Llamamos la atención, a pesar de que parece resultado de una corrección, sobre la transposición semper hoc en Z. También destacamos las dos omisiones observables en $\mathrm{Y}$ y no en $\mathrm{Z}$.

Tampoco llegan al medio centenar las divergencias entre $Z$ y A. Empleando los mismos criterios de selección, es decir, excluyendo las variantes menores, la relación de disimilitudes es ésta:

\begin{tabular}{|c|c|c|c|}
\hline & $\mathrm{Z}$ & $\mathrm{A}$ & \\
\hline $276 r, a, 4-5$ & multa & multis & $(=\mathrm{G})$ \\
\hline $276 \mathrm{r}, \mathrm{a}, 11$ & molestiam $\left(Z^{\mathrm{c}}\right)$ & molestiam que & (= EGHMNOSUVY) \\
\hline $276 r, a, 11$ & presenti $\left(Z^{c}\right)$ & presentis & (= GHMNSUVY) \\
\hline $276 r, a, 31$ & se & om. & (=EGHNO) \\
\hline $276 \mathrm{r}, \mathrm{b}, 12$ & regioni fructibus & om. & $(=\mathrm{G})$ \\
\hline $276 r, b, 15$ & alii & ali & $(=\mathrm{G})$ \\
\hline $276 \mathrm{v}, \mathrm{b}, 8$ & occulis & oculis & (= HMNOSUVY) \\
\hline $277 \mathrm{r}, \mathrm{a}, 10$ & Iudaicus & Iudaycus & (= GMNOUVY) \\
\hline $277 \mathrm{r}, \mathrm{a}, 13$ & Isaac & Ysaac & (= EGHNSUVY) \\
\hline
\end{tabular}

105 Indicamos con $\mathrm{Z}^{\mathrm{c}}$ la posible corrección o alteración del texto, pues tras molestiam y presenti observamos raspaduras y hoc se sitúa en el intercolumnio, como si tal posición subsanase su omisión inicial. 


$\begin{array}{llll}277 \mathrm{r}, \mathrm{a}, 18 & \text { mihi } & \text { mici } & (=\mathrm{EGHS}) \\ 277 \mathrm{r}, \mathrm{b}, 7 & \text { fili } & \text { filii } & (=\mathrm{H}) \\ 277 \mathrm{v}, \mathrm{a}, 19 & \text { Iudaicus } & \text { Iudaycus } & \text { (= GHMNUY) } \\ 277 \mathrm{v}, \mathrm{a}, 23 & \text { a } & \text { om. } & \text { (= GSUV) } \\ 277 \mathrm{v}, \mathrm{b}, 11 & \text { lectionis } & \text { lectiones } & \text { (= EM) } \\ 277 \mathrm{v}, \mathrm{b}, 28 & \text { ac } & \text { hac } & \text { (= GUVY) }\end{array}$

$6^{\circ}$.- El manuscrito al que remite $\mathrm{Z}$ es anterior - ¿en dos décadas? - al códice de Magio (Y) y, probablemente, en medio siglo, al tabarense. Por lo tanto, como hemos señalado ya, se situaría «a la cabeza» de la familia II (en propuesta de Neuss), teniendo en cuenta los beatos supervivientes. La colación realizada corrobora esta afirmación.

Analizando coincidencias y discrepancias de texto, es evidente que $Z$ no fue el modelo de Y. Sin embargo, tal posibilidad cabría en el caso del tabarense, manuscrito con texto más deturpado que $\mathrm{Z}$. En todo caso, se advierte una cierta dependencia con respecto a $\mathrm{Z}$ de los testigos de la «segunda clase» de Sanders, la «rama IIb» de Neuss (y Williams) o «tercera redacción» revisada de Klein ${ }^{106}$.

En definitiva, el camino interno nos conduce claramente a la familia II de Neuss. $Z$ presenta un texto más completo que el de otros ejemplares antiguos de la misma rama (como $\mathrm{Y}$ y A) y sus divergencias con el manuscrito más alejado $(\mathrm{H}$, de la rama $\mathrm{I})$ apenas suponen un tercio de las más de cuatrocientas lecturas tomadas en consideración. $\mathrm{El}$ análisis textual indica que es $\mathrm{Z}$ una copia temprana, si tenemos en cuenta las fechas de ejecución de los restantes testigos de la obra. Proponer una ubicación segura en el stemma es imposible, debido al escaso texto conservado ${ }^{107}$, pero sí podríamos apuntar con reservas

$106 \mathrm{Y}$ ello a pesar de que, como se pone de manifiesto en los ejemplos siguientes, $\mathrm{Z}$ se sitúa más próximo en algunos casos al grupo MSUVY:

$\begin{array}{llll} & \text { Z } & \text { MSUVY } & \text { A G } \\ 276 r, a, 4-5 & \text { multa } & \text { multa } & \text { multis } \\ 276 r, b, 12 & \text { regioni fructibus } & \text { regioni fructibus } & \text { om. } \\ 276 \mathrm{r}, \mathrm{b}, 15 & \text { alii } & \text { alii } & \text { ali } \\ 276 \mathrm{v}, \mathrm{a}, 25 & \text { semper hoc } & \text { hoc semper } & \text { semper hoc }[+\mathrm{F}]\end{array}$

La última variante citada es especialmente significativa para mostrar la que denominamos «dependencia» de los citados testigos visigóticos (A, G, F) y de otro manuscrito más tardío de la misma rama: el Beato de San Andrés de Arroyo. La transposición semper hoc creemos, lo hemos señalado en varias ocasiones, que es resultado en $\mathrm{Z}$ de una intervención correctora para introducir hoc, omitido inicialmente. El Beato de San Andrés de Arroyo omite hoc y los ejemplares A, F y G heredan la transposición igenerada en $\mathrm{Z}$ ?.

107 Teniendo en cuenta que ni siquiera es sencillo hallar la posición de manuscritos completos debido a «la falta de una edición en que se analicen seriamente todos los detalles textuales» (M. C. DÍAZ Y DíAZ, La tradición, p.177, nota 61). Cabe incluso la posibilidad de que un volumen obra de más de una mano sea copia de dos modelos distintos. Al respecto del Beato de Tábara apunta M. C. Díaz y Díaz: «Proba-

Textos medievales

Hispania Sacra 55 (2003) 
una posición cercana al punto en el que se dividen las ramas secundarias IIa y IIb de Neuss o en el inicio de la rama IIb de acuerdo a la propuesta más reciente de Klein ${ }^{108}$, mostrando esta familia una dependencia mayor del volumen al que remiten los manuscritos zamoranos ${ }^{109}$.

Si pasamos del plano textual al geográfico, la cercanía de $\mathrm{Z}$ a los citados $\mathrm{A}$ e Y, seguidos de S, M, U, V y G, parece introducir los fragmentos del A.H.P. zamorano en territorio leonés. Hemos de apuntar asimismo que, por otra parte, los dos manuscritos más próximos a $\mathrm{Z}$ se relacionan estrechamente con el scriptorium de Tábara.

\section{EL CAMINO DE LOS FRAGMENTOS.}

Una tercera - y última - vía que cabe abrir para contextualizar en la medida de lo posible nuestro beato, la constituye el itinerario seguido por los dos pergaminos que ahora custodia el A.H.P. de Zamora, final del recorrido. Es un trayecto vital de casi once siglos, pero sólo podemos reconstruir el último tramo.

Ambas piezas se extrajeron de protocolos del notario Alonso de Villagómez correspondientes a los años 1622 y 1623 (signatura 9036) ${ }^{110}$. El escribano ejercía por entonces su labor en Puebla de Sanabria, localidad sita en el extremo noroccidental de la actual provincia zamorana. Los fragmentos 276 y 277 sirvieron de portadillas para dar inicio a las escrituras fechadas en los años 1622 y 1623 respectivamente. Este uso residual de los pergaminos ${ }^{111}$, tan alejado de la función del manuscrito al que pertenecieron originariamente, posibilitó su supervivencia y permite fijar su procedencia inmediata - Puebla de Sanabria - y la fecha de entrada en el Archivo Histórico Provincial: el 16 de

\footnotetext{
blemente cuando la tradición de los Beatos se estudie a fondo, se descubrirá que la primera parte del Tabarense, la que dejó adelantada Magio, está emparentada con el Beato Morgan» (Ibidem).

108 Cf. P. K. KLEIN, Beatus de Liébana.Codex Urgellensis, p. 86.

${ }^{109} \mathrm{Si}$ tenemos en cuenta la propuesta de J. W. Williams se hallaría en la rama IIa, tal vez en el punto en el que arranca la IIb.

110 Esta signatura figura, a lápiz, en la zona de cabeza del fragmento $276 \mathrm{r}$ y del $277 \mathrm{v}$. El fragmento 276 sirvió para dar inicio al protocolo correspondiente al año 1622, fecha que aparece explícitamente en cuatro ocasiones sobre la pieza. El fragmento 277 , invertido, se utilizó como portadilla de los textos de 1623, año que figura en dos anotaciones. El legajo conserva aún la tapa posterior del conjunto de escrituras correspondiente al año 1623 , un folio de pergamino con algunas pruebas de pluma.

${ }^{111} \mathrm{Al}$ igual que tantos otros testigos de libros medievales del mismo fondo archivístico, los fragmentos 276 y 277 han llegado a nuestras manos notablemente deteriorados: oscurecido y desgastado el soporte, con manchas de diverso origen (polvo, vertido de líquidos), daños consecuencia directa de las manipulaciones efectuadas para utilizar los folios como portadillas de legajos notariales (recorte, dobleces, orificios de costura, anotaciones relativas al contenido de los papeles protegidos, etc.), garabatos, probationes pennae y operaciones aritméticas.
} 
septiembre de 1961 ingresaron los fondos procedentes del distrito notarial sanabrés ${ }^{112}$.

Los dos folios del beato no proporcionan información alguna sobre su circulación antes de llegar a manos del notario. Pensamos que al escribano Villagómez. no debió de resultarle difícil conseguir pergamino viejo ${ }^{113}$ con el que encuadernar sus registros de escrituras, pues la citada villa sanabresa se ubica en lugar privilegiado, como cruce de caminos, y en una comarca con importantes enclaves monásticos desde el medievo ${ }^{114}$. Entre estos cenobios cabe destacar uno, por su temprano origen - primera mitad del siglo $\mathrm{X}^{115}$ - y su larga pervivencia (hasta la Desamortización): San Martín de Castañeda. De este monasterio, sabemos, sí procedían otras piezas utilizadas por Alonso de Villagómez para proteger sus protocolos. Es el caso del fragmento 275 del mismo fondo archivístico ${ }^{116}$, folio incompleto de un ejemplar pregótico de las Enarrationes in psalmos agustinianas que presenta la siguiente anotación:

«Estos pergaminos los traxe de Sant Martín de Castanera, que me los dio Fray Bas ...»117.

¿Entre estos pergaminos se hallaban los dos testigos del beato? No podemos afirmarlo, pero tampoco descartamos tal procedencia.

112 Cf. F. FERrero Ferrero, El Archivo Histórico Provincial de Zamora, fuente indispensable para el estudio de la historia de Zamora: Primer Congreso de Historia de Zamora, vol.I. Fuentes documentales para la historia de Zamora, Zamora 1989, p.157.

113 Cuando describe el fondo bibliográfico del monasterio de Santa María de Carracedo, advierte Ambrosio de Morales «Libros han tenido mucho, y hanlos dado para pergamino viejo...» (Viage de Ambrosio de Morales por orden del rey D. Phelipe II a los Reynos ar León, y Galicia, y principado de Asturias para reconocer las reliquias de Santos, sepulcros reales, y libros manuscritos de las Cathedrales, y Monasterios, Madrid 1765, p. 170).

114 Cf. L. ANTA LOREnZo, El monasterio de San Martín de Castañeda en el siglo X: Stvdia Zamorensia, $2^{a}$ etapa, 3(1996)35-36) e I. MARTín VISO, Fragmentos del leviatán. La articulación política del espacio zamorano en la Alta Edad Media, Zamora 2002, pp. 97 (nota 186) y p. 99.

115 Se han apuntado dos años para la fundación: 916 y 921 . A propósito de esta cuestión, en la que ahora no podemos detenernos, véanse A. GONZÁLEZ BLANCO, La cristianización de Zamora: Primer Congreso de Historia de Zamora, II, Prehistoria y Edad Antigua, Zamora 1990, p. 291, G. CAVERO DOMÍNGUEZ, Los mozárabes leoneses y los espacios fronterizos: La Península Ibérica en torno al año 1000, León 2001, p. 246 y L. ANTA LORENZO, El monasterio p. 40.

116 Procede del protocolo signado con el número 9038.

117 Recortado el folio para adaptarlo a las dimensiones del protocolo, ha desaparecido el nombre del monje y un segundo renglón de texto, muy breve, aparece encubierto por borrones y manchas en el pergamino.

Textos medievales

Hispania Sacra 55 (2003) 


\section{NUEVOS CAMINOS.}

¿Convergen en algún punto los caminos seguidos? ¿Hallamos al final del triple recorrido las coordenadas de tiempo y espacio que buscamos?

A propósito del primer aspecto, conviene que señalemos cómo la datación que se deduce de la escritura - la primera mitad del siglo X - no contradice los resultados obtenidos tras el análisis del texto. Por otra parte - icasualmente?el itinerario retrógrado seguido por los dos fragmentos podría detenerse en un monasterio - San Martín de Castañeda - fundado en la misma época. Situar el beato en el tiempo con cierta aproximación es posible: vio la luz en la primera mitad del siglo X, pero ¿dónde?

A diferencia de lo que atañe a la edad, ubicar geográficamente el origen del libro plantea muchos problemas.

En primer lugar, los caminos elegidos no siempre conducen a un mismo punto. Un buen ejemplo lo constituye la relación entre el enigmático beato Vitr. 14-1 de la Biblioteca Nacional y los fragmentos del A.H.P. zamorano. Este códice mutilado, de origen desconocido, es el más emparentado gráficamente con Z; sin embargo, muy cercano en la forma, el texto de este manuscrito ( $\mathrm{N}$, inserto en la rama I de Neuss) es uno de los más alejados de las piezas zamoranas. La vía externa une $\mathrm{Z}$ y $\mathrm{N}$, pero la vía interna los distancia.

En segundo lugar, aun en los casos en los que ambos caminos -escritura/contenido - se acercan, tampoco es posible fijar un solo punto de convergencia. Es el caso de la relación entre $\mathrm{Z}$ y los beatos de Magio (Y) y de Tábara (A), ambos posteriores a $\mathrm{Z}$ y vinculados, directa o indirectamente, al monasterio tabarense. Son los más próximos a los fragmentos de Zamora en el plano textual; además, la dependencia de $\mathrm{A}$ y de otros ejemplares posteriores de su misma rama con respecto a $Z-0$ algún ejemplar gemelo- es patente. Por otra parte, el análisis gráfico pone de relieve que la escritura de $Z$ evidencia similitudes con diversos manuscritos nacidos unos en lugar desconocido y otros, la mayor parte, en el Reino de León, entre los cuales se hallan los citados $A$ e $Y$-Escalada, Fernando I, Gerona, Tábara, Valcavado-, pero, los copistas de estos ejemplares ¿son también leoneses? M. C. Díaz y Díaz apunta que «como prueba su escritura, Magio era castellano»" ${ }^{118}$.

En definitiva, pensamos que la escritura y su adscripción a un área gráficogeográfica determinada, suponiendo que tal asignación sea fiable, no conduce con seguridad al scriptorium en el que se confeccionó un libro ${ }^{119}$. Pero tampo-

118 M. C. DÍAZ Y DÍAZ, La tradición, p.177.

119 «se sigue discutiendo sobre (...) si determinadas obras son ejemplo de escritura castellana en territorio leonés, o qué papel juegan y hasta qué punto siguen ciertos discípulos los usos, modas o 
co la rama textual a la que pertenece un manuscrito proporciona la clave. Supuesta una misma escuela gráfica para los beatos $\mathrm{Z}$ y N, y la evidencia de dos modelos de familia textual diferente, cabe pensar tanto en la labor de un artífice/escuela que ejerce su tarea en centros distintos sobre modelos sitos en su lugar temporal de trabajo - tal vez el caso de Magio - como en un mismo taller bibliográfico que disponía de, al menos, dos exemplaria del Comentario testigos de diferentes ramas textuales. Esta última posibilidad, la presencia de dos modelos de distinta familia en un mismo territorio, parece fuera de toda duda en el caso del área de influencia tabarense, como señala M. C. Díaz y Díaz:

\begin{abstract}
«Cuando Magio dibuja su preciosa obra en 962 en San Miguel de Escalada, se inicia un nuevo período en la historia de los Beatos (...): como prueba su escritura, Magio era castellano y es probable que el modelo que copió fuera de ese mismo origen. Unos años después inicia el Beato de Tábara, probablemente en zona leonesa sobre un modelo que sirvió, ochenta años más tarde, para copiar, ya con nuevas contaminaciones, el Beato de Fernando I que hoy vemos en la Biblioteca Nacional. Lo que importa ahora subrayar es que otro copista de formación también castellana, el llamado Monio, remata el Beato Tabarense; otro escriba de ambiente y formación análoga produce el de Gerona. Aquí comienzan las dificultades, pues tanto Tábara como el Beato de Gerona dependen de tipos diferentes, y hasta diría que algo alejados, del seguido por Magio. La observación debe ser tenida en cuenta, toda vez que Emeterio se nos presenta en Tábara como discípulo y continuador de Magio; pero ¿en qué medida? ¿Y hasta qué punto esta relación se podría reflejar en el suministro y disponibilidad de modelos?»120.
\end{abstract}

Por otra parte, y tomando nuevamente el texto como hilo conductor, es imposible afirmar que $Z$ se realizó en lugar próximo a la cuna de los beatos de Tábara y, tal vez, Gerona, aunque esta posibilidad, obviamente, no puede excluirse, como tampoco debe rechazarse un origen de $\mathrm{Z}$ en zona del este ${ }^{121}$, li-

\footnotetext{
hábitos traídos por sus maestros desde otras regiones» (J. A. FERNÁNDEZ FLóREZ, Fragmentos, p. 409 , nota 35 ).

${ }^{120}$ M. C. DíAZ Y DíAZ, La tradición, p. 177. «Llegué a decir que Magio manejaba un modelo que, grosso modo, yo llamaba castellano (...) pero señalé también que, para el texto de Tábara, debía haber otro manuscrito emparentado con él, pero diferente, porque hay algunas divergencias de texto evidentes, hasta el punto de no poder identificarlo con el modelo de Magio. Es decir, el modelo de Magio no es el modelo del llamado códice de Tábara. Debemos pensar incluso en más de un modelo» (M.C. Díaz y Díaz, intervención en el Coloquio tras la exposición de P. K. Klein sobre la tradición pictórica de los Beatos, Actas del Simposio, vol. I., p. 110).

121 Con respecto a los códices de Valcavado, Tábara y Gerona, advierte J. A. Fernández Flórez: «La mayor proximidad del texto de Valcavado (dentro de los por nosotros analizados) se produce con el de los Beatos T y G. Queremos recordar que si tanto los beatos de Tábara y Gerona, por un lado, como el de Valcavado, por otro, parecen ser productos de sendos escritorios del oriente del reino de León, tales planteamientos se podrían ver ahora reforzados por el indudable parentesco textual» ( $E l$ Apocalipsis y Beato de Liébana, p. 20).
}

Textos medievales

Hispania Sacra 55 (2003) 
mítrofe con scriptoria castellanos ${ }^{122}$, lo que explicaría ciertas coincidencias con códices del área de influencia emilianense ${ }^{123}$ y que no se constaten tantas discrepancias con manuscritos especialmente significativos de la rama I como se observan en otros testigos de la obra ${ }^{124}$ ¿Las peculiaridades del texto nos conducen a un ámbito de contacto entre el «grupo leonés» y el «grupo castellano-riojano» de beatos?

Expuestas ya las razones por las que desconfiamos de cualquier adscripción espacial irrefutable del nuestro y de otros ejemplares sin información explícita sobre su identidad ¿Es posible, no obstante, traducir de algún modo a términos geográficos la contradictoria relación $\mathrm{Z}-\mathrm{N}$, la vinculación de $\mathrm{Z}$ con el manuscrito de Magius y, especialmente, con el tabarense y sus derivados, el parentesco menos intenso con otros beatos anteriormente citados -Fernando I, Gerona, Valcavado, Urgel-, los contactos con los testigos de la primera rama textual y la probable estancia de los dos fragmentos zamoranos en el monasterio de San Martín de Castañeda?

Entendemos que, a partir de lo anteriormente expuesto, sí cabe una lectura en el plano espacial, pero esta lectura introduce los fragmentos del A.H.P. zamorano en un territorio más amplio del que desearíamos, no conduce a un punto concreto. Es un marco limitado al norte por San Miguel de Escalada y Valcavado, constituyendo este último cenobio también el vértice oriental. Al sur, el término se situaría en Tábara y el extremo oeste podría marcarlo San Martín de Castañeda. Cualquiera de los centros citados pudo ser el origen que buscamos. Sí, también el monasterio sanabrés, suficientemente antiguo para ver nacer un manuscrito visigótico ${ }^{125}$ y en cuya iglesia se conserva una inscripción fechada en 921, muy similar a la que en su día se dispuso sobre una de las puertas de entrada al templo de San Miguel de Escalada ${ }^{126}$. En el espacio terri-

122 «Con los códices conservados, podríamos hablar de un núcleo inicial de copia y difusión de los Comentarios en los territorios orientales del Reino de León en contacto con Castilla» (J. A. FERNÁNDEZ FLÓREZ, El Apocalipsis y Beato de Liébana, p. 19).

123 Sirva de ejemplo la siguiente variante: $\mathrm{Z} 277 \mathrm{v}$, a, 16 e[te]rre (?): eterre $\mathrm{H}$. No olvidemos, asimismo, que uno de los fragmentos emparentados textualmente con $\mathrm{Z}$, el fragmento $\mathrm{F}$, se conserva actualmente en el monasterio de Silos.

124 Como muestra, la colación parcial que lleva a cabo J. A. FERNÁNDEZ FLóREZ, Fragmentos, pp. 415-416.

125 Tal vez albergó un scriptorium pero no contamos con objetos escritos coetáneos del cenobio - libros, documentos- para establecer comparaciones gráficas que apoyen esta hipótesis, pues el primer documento original conservado de San Martín de Castañeda se fecha en 1018 y presenta escritura visigótica cursiva (Madrid, A.H.N., Clero, pergaminos, carp.3563-n12). La distancia de casi un siglo entre el Beato y el diploma y la modalidad escriptoria impide cualquier estudio comparativo.

126 Editada, entre otros, por A. DE MORALES, Corónica General de España, vol. VIII, Madrid 1791, p. 241; M. GÓMEZ-MORENO, Iglesias mozárabes. Arte español de los siglos LX a XI, Madrid 1919, pp. 169-170, p. 169, M. GUTIÉRREZ ÁlVAREZ, Corpus inscriptionum Hispaniae Mediaevalium. 
torial que hemos acotado se ubican, además, dos monasterios que pudieron mantener relaciones con San Miguel y/o San Martín. Nos referimos a San Juan-San Isidoro de León ${ }^{127}$ y a Sahagún ${ }^{128}$. También en estos, o en ninguno, pudo ver la luz el nuevo Beato.

¿Dónde nació el beato del A.H.P zamorano? Era una de las preguntas con las que abríamos el presente estudio, cuestión a la que, finalmente, no podemos dar respuesta. Hemos llegado no a un taller sino a un relativamente amplio ámbito geográfico que surca una red de monasterios, relacionados entre sí por diversas razones: espirituales, culturales, económicas... Un territorio en el que un conjunto de hitos dibujan otros caminos. Rutas que recorren, o pueden recorrer, copistas e iluminadores de libros, redactores y lapicidas de inscripciones... Vías que siguen o pueden seguir ejemplares transmisores del Comentario $^{129}$ - completos, mutilados o reducidos a fragmentos-, sendas que recorren comunidades que buscan mejores condiciones de vida, itinerarios de lectores y poseedores de libros que se desplazan llevando consigo enseres y co-

I/1. Zamora. Colección epigráfica, Turnhout-León 1997, pp. 17-18 y M. PÉREZ GONZÁLEZ, El latín del siglo X leonés a la luz de las inscripciones: Actas II Congreso Hispánico de latín medieval, León 1998, pp. 164-165). Es muy interesante su configuración en "prosa rítmica» (M. PÉREZ GONZÁLEZ, O.c., pp. 167-169). Su especialísima vinculación con la de San Miguel de Escalada es señalada por M. RISCO, España Sagrada. XXXV, Madrid 1784, p. 311, M. GÓMEZ-MORENO, Iglesias mozárabes. Arte español de los siglos IX a XI, Madrid 1919, p. 169, A. QUINTANA PRIETO, El Obispado de Astorga en los siglos IX y X, Astorga 1968, p. 139 y V. GARCíA LOBO, Las inscripciones de San Miguel de Escalada, Barcelona 1982, pp. 64-65.

127 En uno de los obituarios medievales de San Isidoro de León (ASIL, Códice IV, ff.38r-57v) figuran entradas datables a finales del siglo XII-principios del siglo XIII que hacen alusión a Castañeda (f.53r) y a Escalada (f.41r), hecho que indica cierta vinculación, al menos de carácter espiritual, entre la canónica y los dos monasterios citados.

128 Este poderoso cenobio, situado al este del Reino de León, fue cuna, parece, de, al menos, tres beatos de los siglos XI (fragmentos de la Chancillería de Valladolid y Montserrat, Beato de Osma) y XII (el Beato Corsini, cf. P.K. KLEIN, Beatus de Liébana. Codex Urgellensis, p. 34), todos insertos en la rama I. Bien pudo haber contado en época temprana con uno o más ejemplares de la obra atribuida a Beato y no necesariamente de la misma familia textual. Como señala J.A. Fernández Flórez «No parece imaginable que el gran cenobio del Cea estuviera sin la obra de Beato hasta esos momentos finales del siglo XI (...) En el archivo de un monasterio muy próximo al de Sahagún y dependiente de él, como lo fue el de San Pedro de las Dueñas, se nos ha conservado un folio de un Beato del siglo X, que muy bien podría haber pertenecido a un primitivo Beato del monasterio de Sahagún» (El Apocalipsis y Beato de Liébana, p.16). En el plano económico, debemos señalar cómo este cenobio «extendió sus dominios por tierras zamoranas, lejos de sus límites originales» (cf. S. MORETA VELAYOS, La sociedad zamorana en los siglos X-XIII: Historia de Zamora I. De los orígenes al final del medievo, Zamora 1995, p. 548). En sentido inverso, no podemos olvidar que San Martín de Castañeda constituyó un dominio que alcanzaba «territorios mucho más alejados como Coyanza y Tierra de Campos» (...) (L. ANTA LORENZO, O.c., p. 32, véase también Ibidem, p. 46) y mantuvo relaciones comerciales con monasterios de Tierra de Campos como Vallispopuli. (Ibidem, p.36, nota 27).

129 «En términos generales se puede decir que los Beatos viajaron mucho» (J. A. FERNÁNDEZ FLÓREZ, El Apocalipsis y Beato de Liébana, p. 16).

Textos medievales

Hispania Sacra 55 (2003) 
nocimientos... Un espacio, en definitiva, de artífices que viajan y de libros viajeros.

\section{APÉNDICE ${ }^{130}$.}

\section{[Fragmento 276r, a]}

mundo teneatur, loqui contra $/^{2}$ [alio]s libere recusat, ne ipsa ${ }^{131} \beta^{3}$ [uit]e sue quietem perdat. Isti $/ 4$ uirtus prophetie data est mul $-\rho^{5}$ ta iam, que uentura sunt, preui- $/^{6}$ det, sed tamen presentis proxi $-\rho^{7}$ mi egritudinem conspiciens $/^{8}$ atque conpatiens, non ualet $/^{9}$ curare. Illi data est curatio- ${ }^{10}$ nis gratia, atque a corpore proximi $/{ }^{11}$ molestiam in presenti ${ }^{132}$ ora- $/{ }^{12}$ tionibus repellit, sed tamen $/{ }^{13}$ quid se ipsum paulo post seqvatvr, $/ /^{14}$ ignorat.

${ }^{130}$ Realizamos la reproducción del texto de acuerdo a los siguientes criterios:

- Respetamos la grafia del original, aunque sea defectuosa.

- La pequeña $u$ sobrepuesta, con forma angular y ligeramente inclinada, la transcribimos por $v$.

- Desarrollamos todas las palabras abreviadas, escribiendo en caracteres cursivos las letras que se han omitido dentro de cada palabra.

- El semicolon asociado a la consonante $q$ se resuelve por medio de $u e$, pese a que en ocasiones la lectura correcta incorporaría el diptongo $a e$.

- El texto desaparecido o ilegible por roce del pergamino, orificios, arrugas, manchas de diverso origen, pruebas de pluma, etc. y que suplimos en la transcripción, lo situamos entre corchetes [ ]. Tomamos como base para la restitución, con excepciones que indicamos en nota a pie de página, las ediciones de H. A. Sanders y E. Romero Pose reiteradamente citadas. En caso de lecturas divergentes optamos por la que más se ajusta a los rasgos conservados.

- Para facilitar la impresión, se señala la e caudata subrayando esta vocal. No descartamos que en algunos casos la cauda haya pasado desapercibida debido al deficiente estado de conservación de ciertas zonas.

- Las letras omitidas inicialmente y añadidas entre renglones las introducimos en paréntesis angulares $<>$.

- Especificamos el folio - recto o vuelto- y la columna a la que se refiere el texto por medio de indicaciones explícitas ( $\mathrm{a}=$ primera columna, $\mathrm{b}=$ segunda columna).

- Advertimos el cambio de renglón mediante /. Pese a que no es habitual en la transcripción de textos librarios, incorporamos el número de cada renglón, con el fin de facilitar la localización de los términos que hemos recogido al abordar las cuestiones referidas a la filiación del manuscrito y para ubicar las variantes con respecto a otros ejemplares cotejados.

- En nota a pie de página señalamos las modificaciones que se efectuaron en el original (incorporación entre renglones de letras inicialmente omitidas, enmiendas y raspaduras)

- Destacamos en negrita los caracteres realizados en tinta roja.

${ }^{131}$ Los desperfectos en el pergamino sobre esta palabra impiden saber si superpuesto a la $a$ se dispuso un signo de abreviación.

${ }^{132}$ Tras molestiam y después de presentis sendas raspaduras. A continuación de molestiam los rasgos conservados podrían corresponder a la abreviatura $\mathrm{q}^{\mathrm{s}}$. 
Mira itaque dispen- $-{ }^{15}$ satione omnipotens Deus sic in electis $/{ }^{16}$ suis sua dona dispensat, $/{ }^{17}$ ut et isti det quod illi negat, $/{ }^{18}$ [e]t alterius maius quod alteri $/{ }^{19}$ minus tribuat, quaten $u$ s dum ${ }^{20}$ uel iste habere illum conspicit, $I^{21}$ quod ipse non habet, uel ille ${ }^{22}$ hunc maius accepisse conside- ${ }^{23}$ rat, quod sibi minus adesse pen- $-/^{24}$ sat, dona Dei alter in altero, ${ }^{25}$ id est, uicissim, homines admiren- $/^{26}$ tur, atque ex hac ipsa admi- $/^{27}$ ratione humilietur alter ${ }^{28}$ alteri, et, quem uidet habere, $/^{29}$ quod non habet, eum diuino $/{ }^{30}$ iudicio sibi prelatum putet. $/^{31}$ Alis ergo suis uicissim se animalia

\begin{abstract}
2 alios libere recusat, ne $\mathrm{O}^{\mathrm{c}} \quad$ / ipsa: ipse O ipsam E U V 3 uite: uite E M N O S U V $\mathrm{Y} /$ sue: sue $\mathrm{E} \mathrm{H} \mathrm{MN}$

O S U V Y / quietem: quietem U V / isti: istis A/isti $A^{c} \quad$ istis G 4 prophetie: prophetie A G profetie E profetie $\mathrm{H}$ 4-5 multa: multis A G 5 q que H Y 5-6 preuidet: preuidet $\mathrm{H}$ M N S V Y 6 sed: set G

/ presentis: presentis $\mathrm{H} \mathrm{OS} 7$ egritudinem: egritudine $\mathrm{E} \mathrm{H} \mathrm{N} \mathrm{O} \mathrm{/} \mathrm{conspiciens:} \mathrm{conspitiens} \mathrm{G} \mathrm{/}$ conspiciens: atque conspiciens add. $\mathrm{N} 8$ atque: adque M U V/ non: no U 8-9 conpatiens: compatiens V 10 atque: adque $\mathrm{M} \mathrm{V} \mathrm{/} \mathrm{a:} \mathrm{<a>} \mathrm{U} 11$ molestiam: que add. A G M O S U V Y que add. $\mathrm{E} \mathrm{H} \mathrm{N} \mathrm{/} \mathrm{presenti:} \mathrm{presentis} \mathrm{A} \mathrm{G} \mathrm{M} \mathrm{N} \mathrm{U} \mathrm{V} \mathrm{Y} \mathrm{presentis} \mathrm{H} \mathrm{S}$ presentis $\mathrm{E} /$ presenti $\mathrm{E}^{\mathrm{c}} /$ presenti: est add. $\mathrm{E} \mathrm{H} N \mathrm{O} S 12$ repellit: reppelli O reppellit $\mathrm{E} \mathrm{G} \mathrm{V} /$ sed: set $\mathrm{G} 13$ quid: qui M U

quod N / se ipsum: om. O / 15 electis: electis S U celestis E celestis $\mathrm{H} 16$ sua: om. V 17 et: om. E 18 alterius: alterius A/alteri $A^{c} 20$ uel: uult $G 21$ habet: abet $G 25$ uicissim: uicesimi G / homines: omnes $\mathrm{O} 26$ atque: adque $\mathrm{E} \mathrm{V} \mathrm{/} \mathrm{ex:} \mathrm{a} \mathrm{add.} \mathrm{G} \mathrm{/} \mathrm{ac:} \mathrm{ac} \mathrm{H}$ om. $\mathrm{O} 27$ humilietur: humiletur H 28 et: ne O / habere: $a b<$ e >re H 29 non: om. O / habet: abet $\mathrm{H} 30$ prelatum: prelatum H S 31 Alis: aliis E / ergo suis: tr. E / uicissim: uicissime G / se: om. A E G H N O
\end{abstract}

\title{
[fragmento 276r, b]
}

$/^{1}$ [feriunt, cu]m sancte mentes [a]1[ternis] $/^{2}$ se uirtutibus tangunt, et tan- $\beta^{3}$ gendo excitant, atque excitat $[\mathrm{e}]^{133} / 4$ ad profectum uolant.

Alis ergo $/ 5$ se tangunt, quia inde se uicis- $/ 6$ sim ad profectum excitant, un$\Gamma$ de uolant.

Hec itaque omnipotens $\mathbf{s}^{134}$ Deus agit $/{ }^{8}$ in cordibus hominum, quod facit in $/ 9$ regionibus terrarum. Poterat namque $/{ }^{10}$ unicuilibet regioni fructus tri- $/{ }^{11}$ buere, sed si una quelibet regio $/ /^{12}$ alterius regioni fructibus non in- $/^{13}$ digeret, communionem cum altera $/{ }^{14}$ non habuisset. Unde fit ut huic $/^{15}$ uini, alii uero olei habundantia $m /{ }^{16}$ tribuat; hanc multitudinem $/{ }^{17}$ pecodu $m$, illa uero ubertate ha$/ /^{18}$ bundare facit frugum, ut quum $/{ }^{19}$ illa deferat, quod ista non habet, ${ }^{20}$ et ista

\footnotetext{
${ }^{133}$ Los rasgos conservados del último carácter de la palabra nos acercan a la vocal $e$ y no a una $a$.

${ }^{134} \mathrm{Se}$ advierte una duda entre oms y omps. Parece que inicialmente se escribió omps (omnipotens) y luego se situó una $s$-en tinta más oscura- sobre la $p$.

Textos medievales Hispania Sacra 55 (2003)
} 
reddit, quod illa non detulit, ${ }^{21}$ per communionem gratie sibi simul etiam $\rho^{22}$ diuise terre coniuncte sint. Sicvt enim ${ }^{23}$ regiones terrarum, ita sunt mentes sanctorum, ${ }^{24}$ que dum uicissim sibi conferunt, qvasi ${ }^{25}$ fructos suos regiones regionibus im- $\left.\right|^{26}$ pendunt ut in una omnes caritate ${ }^{27}$ iungantur. Sed inter hec scien${ }^{28} \mathrm{dum}$ est, quia sicut electi quique ${ }^{29}$ hoc semper in aliis adtendunt, qvod ${ }^{\beta 0}$ a Deo melius acceperunt, cum ipsi, $\beta^{11}$ ut eos sibi in cogitatione preferant, se

1 [cu]m: dum N / sancte: sancte N O S Y 2 se uirtutibus: seruitutibus N / tangunt: tagvnt Y 3 excitant: exitant $\mathrm{O} /$ atque: adque $\mathrm{M}^{*}$ adque $\mathrm{V} /$ excitat[e]: ex $<\mathrm{c}>$ itate $\mathrm{A}$ exitate $\mathrm{G} \mathrm{O}$

excitare $\mathrm{H} \quad$ excitate $\mathrm{S}$ exciccitate $\mathrm{M} /$ excitate $^{\mathrm{c}} \mathrm{M}^{\mathrm{B}}$ 3-5 $<$ atque excitate ad profectum $>$ uolant <aliis <ergo> se tangunt> $\mathrm{E}^{\mathrm{c}} 6$ excitant: exitant G O $7 \mathrm{Hec}$ : hec A G hoc E H N O 8 quod: quod U/quos $U^{c} 9$ poterat: poterant $S \mathrm{U} V /$ namque: om. S U V 10 unicuilibet: unicuilibiet $\mathrm{G}^{\mathrm{c}} /$ regioni: regione V 11 quelibet: quelibet $\mathrm{H}$ M O S V Y / regio: <regio> U 12 regioni fructibus: om. A G 13 communionem: conmunionem $\mathrm{E} /$ cum: quum O / altera: altero $\mathrm{H} 14$ habuisset: abuisset $\mathrm{H} \mathrm{U} /$ ut: om. $\mathrm{O}$ / huic: uhic $\mathrm{N} 15$ alii: ali A G / habundantiam: abundantiam $\mathrm{H}$ habundantia E N O

16 tribuat: tribuit $\mathrm{N} /$ tribuat $\mathrm{N}^{\mathrm{c}} /$ multitudinem: multitudine $\mathrm{E} 17$ pecodum: pecodum $\mathrm{A} /$ pecudum $\mathrm{A}^{\mathrm{c}} \quad$ peccodum V/illa: illa A/illam $\mathrm{A}^{\mathrm{c}}$ / ubertate: hubertate A G M S U V Y 17-18 habundare: abundare E O 18 facit: faciat E H N O / quum: cum H M N U Y 19 habet: abet G H 20 reddit: reddidit V / illa: ista G 21 communionem: conmunionem N / gratie: gratie A G H / sibi: siui N / etiam: etiam S U V Y 22 diuise: diuise A E G H N O U V Y / terre: terre A G H U / coniuncte: coniuncte $S 23$ mentes: men<tes> E 24 que : que A E G N 25 fructos: fructus A/fructos $A^{c}$ 25-26 impendunt: inpendunt E H M S U V Y 26 in: om. N / caritate: karitate S 27 hec: hec E H M O S U V Y 28 electi: electi S 29 hoc: se add. E H N / in: om. E H N O / aliis: ali<i $>$ S Uc 30 a: $<\mathrm{ad}>\mathrm{G} / \mathrm{cum}$ : quum E H N 31 ut: $<\mathrm{ut}>\mathrm{G} /$ cogitatione: cogitioni H cognitione $\mathrm{M} /$ preferant: preferant $\mathrm{H} S \mathrm{Y}$

\section{[fragmento 276v, a]}

$/^{1}$ illis in humilitate substernunt, $f^{2}$ ita reprobor $u m$ mens numquam con$\beta^{3}$ siderat quid alter boni amplius $\beta^{4}$ quam alter habeat. Neque enim $\beta^{5}$ pensant, quod bona spiritaliter $\delta^{6}$ acceperint et ipsis desint, sed qve $/^{7}$ bona ipsi, et que mala adsint $\beta$ alteri. Et quum omnipotens Deus ad hoc $/ 9$ uirtutes singulis diuidat, ut al- $/^{10}$ terum alteri in cogitatione humi- $/^{11}$ liet, ad hoc reprobi pertraunt bo$/^{12}$ num quod acceperunt, ut ex eo in e- $/^{13}$ latione perdantur, dum semper $/ /^{14}$ considerant bona, que ipsi habent $/{ }^{15}$ et alii non habent, et numquam $/{ }^{16}$ perpendere studeant, quanta $/{ }^{17}$ bona alii habeant, et ipsi non $/{ }^{18}$ habeant. Quod ergo diuina $\mathrm{pi}-/^{19}$ etas in augmento disponit hu- $/^{20}$ militatis, hoc mentes reprobe in $/^{21}$ argumento uertunt elationis. ${ }^{22}$ Et ex diuersitate muner $u m$ ab eo defi- $/{ }^{23}$ ciunt, unde crescere in humilita- ${ }^{24}$ tis bona debuerunt. 
Propter hoc ergo $/{ }^{25}$ necesse est, fratres karissimi, ut in uobis semper hoc ${ }^{135}$ ${ }^{26}$ debeatis aspicere quid minus ha- $/{ }^{27}$ betis; in proximis uero hoc quod ${ }^{28}$ uobis amplius acceperunt. ${ }^{29}$ Quaten $u s$, dum super uosmedipsos $/^{30}$ eos pro bono quod ipsi habent et $\beta^{31}$ uos non habetis, aspicitis, ad hoc

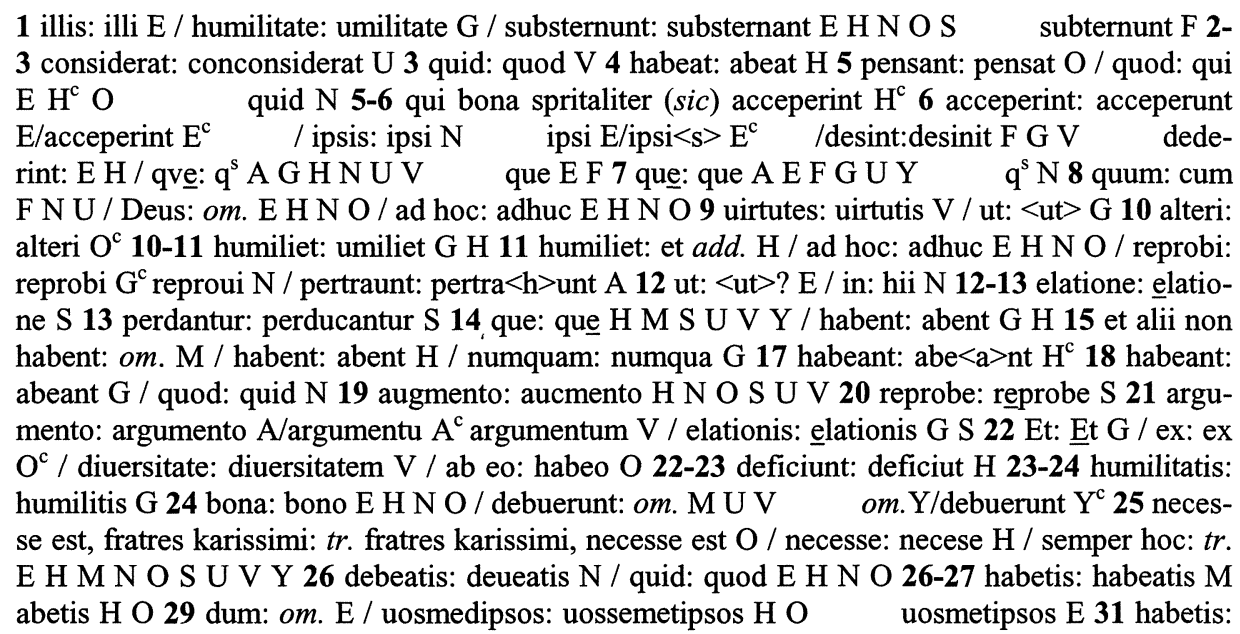
abetis $\mathrm{H}$

\section{[fragmento 276v, b]}

$/^{1}$ quoque obtinendum etiam uos ex $/^{2}$ humilitate crescatis. Si enim $\rho^{\beta}$ et uos in illis accepta bona per- $/^{4}$ penditis, et illi in uobis consi- $/^{5}$ derant dona, que habetis, ui- $/{ }^{6}$ cissim uos alis tangitis, ut $/ 7$ excitati semper ad celestia euoletis.

$/^{8}$ Et intus plena sunt occulis. $/^{9}$ Intus de quod malis occultum sit $/{ }^{10}$ lumen euangelii, quod non nisi $/^{11}$ a sanctis fidei oculis aspicitur; $/{ }^{12}$ et quod ipsi sanc$t$ i humilitate co- $/{ }^{13}$ necti future claritatis reser- $/{ }^{14}$ uantur. Corpora ita[que] anima- $/{ }^{15}$ lium idcirco plena oculis dis- $/^{16}$ cribuntur, quia sanctor $u m$ actio $/^{17} \mathrm{ab}$ om $n$ i parte circumspecta est, $/^{18}$ bona desiderabiliter prouidens, $/^{19}$ mala sollerter cauens. Et hoc ${ }^{20}$ est laboriosior ubi sanctorum mens $/^{21}$ uehementer inuigi$\mathrm{la}[\mathrm{t}]$, ne inere-

135 Omitido inicialmente hoc, se añadió el vocablo al final del renglón, en espacio del intercolumnio.

Textos medievales

Hispania Sacra 55 (2003) 
${ }^{22}$ ant eorum ocul[o]s ${ }^{136}$ et mala sub $/^{23}$ bonorum specie abscondant. ${ }^{24} \mathrm{Cir}-$ cumspecta est ergo uota sanctorum ${ }^{25}$ ne sic sit libera, ut superb[a] sit, ${ }^{26}$ quia sepe superbia excede[t] in uer- $/^{27}$ bis, et uideri appetit libertas $/^{28}$ puritatis; ne sic sit humi[li]s $/^{29}$ ut formidolosa, quia aliqvan- $-^{\beta 0}$ do timor restringit animum, $\beta^{11}$ ut loqui, que recta sunt, non presumat ${ }^{137}$

\begin{abstract}
1 etiam: etiam E S U 2 humilitate: $<\mathrm{h}>$ umilitate $\mathrm{O}$ umilitate $\mathrm{G} 3$ bona: bono $\mathrm{H} \mathrm{3-4}$ perpenditis: prependitis $\mathrm{O} 4$ illi: illis E G 5 dona: bona E / que: que E H M O S V / habetis: abetis H 6 alis: aliis $\mathrm{G} /$ alis $\mathrm{G}^{\mathrm{c}} 7$ excitati: exitat $\mathrm{O} /$ celestia: celestia A O V celesti G / euoletis: euoletis H S 8 plena: pleni O / occulis: oculis A H M N O S U V Y 9 de: dixit E H N

O S / quod: quo<d $>$ V 11 a: ad G / oculis: occulis E S 13 claritatis: claritati E H N / future: future S 13-14 reseruantur: reserbantur H M S V Y 15 oculis: occulis E S 16 actio: hactio V 17 circumspecta: circuminspecta $\mathrm{N} 18$ desiderabiliter: desiderauiliter E N 19 sollerter: solerter $\mathrm{O}$ / cauens: cabens $\mathrm{E} H \mathrm{O}$ cauens: $\mathrm{U}^{\mathrm{c}}$ (margen de canal) 20 laboriosior: laboriosior A/laboriosius $\mathrm{A}^{\mathrm{c}}$ / ubi: ubi add. O 21 uehementer: ueementer $\mathrm{H} \mathrm{M}$ / inuigila[t]: inuigilant $\mathrm{E}$ H 21-22 inereant: inhereant $\mathrm{N}$ inereant $\mathrm{S} 22$ eorum: eorum add. U/anulado mediante puntos $\mathrm{U}^{\mathrm{c}} / \quad$ ocul[o]s: occulos S / et: om. E H O / et mala: tr. N 22-23 sub bonorum: subonorum U V 23 specie: specie A E G O U V Y speciem H 24 circumspecta: circuminspecta N/ uota: uita E H N O S uota Y/ uyta $Y^{\mathrm{c}} 25$ ne: nec E O / superb[a]: superua E G H M N O S V Y 26 superbia: superuia E H N S 26 excede[t]: excedat M exedet $O 27$ libertas: liuertas E 28 ne: nec E G N 31 que: que A E G N O U Y / presumat (o presummat): presummat A E G presummant $\mathrm{H}$ presumat: MNUV presumat OS presumat (o presummat) $\mathrm{Y}$
\end{abstract}

\title{
[fragmento 277r, a]
}

$/^{1}$ non erubuit confiter[i]. Quid est $/^{2}$ quod uestis fratris maioris indui- $/ 3$ tur, nisi quod sacre scripture $/^{4}$ preceptis que maiori populo data $I^{5}$ fuerant, in bona operatione ues- $/{ }^{6}$ titus est? Et eis minor in domo $\Gamma^{7}$ utitur, quem maior foris exiens $/^{8}$ intus reliquid, quia illa gen- $/^{9}$ tilis populus precepta tenet in men- $/^{10}$ te, que Iudaicus populus habere $/{ }^{11}$ non potuit, dum solam in eis $/{ }^{12}$ litteram adtendit. Et quid est $/^{13}$ quod Isaac ${ }^{138}$ eundem filium nescit $/^{14}$ quem benedicit, nisi hoc quod $/{ }^{15}$ de gentili populo Domin $u$ s per psalmis- $/{ }^{16}$ tam dixit: Populum quem non $/{ }^{17}$ cognoui, seruiuit mici, ob au- $/^{18}$ ditu auris obaudiuit mihi? $/{ }^{19}$ Quid est ergo quod presentem non $/^{20}$ uidet, et tamen, que ei in futu- $/^{21}$ ro ueniant, uidet, nisi quod ${ }^{22}$ omnipotens Deus, cum per profetas suos pre${ }^{23}$ dicaret gentilitati gratiam $/^{24}$ prerogandam, eam in presenti $/^{25}$ per gratiam

\footnotetext{
${ }^{136}$ Los rasgos conservados no nos permiten descartar que en lugar de la vocal $o$ se hubiese trazado una $i$.

${ }^{137}$ Parece que se dispuso sobre la palabra un signo de abreviación que daría lugar a presummat.

${ }^{138}$ La primera $a$ se identifica con dificultad, debido a una rotura en el pergamino.
} 
non uidit, que tunc ${ }^{26}$ in errore derelinquid, et tamen $\rho^{27}$ quia hoc quandoque collectu- $/{ }^{28}$ rus erat, per benedictionis gra- $\left.\right|^{29}$ tiam preuidit? Unde idem $/^{30}$ Iacob, gentilis populi figuram $/^{\beta 1}$ tenenti, in benedictione $m$ dicitvr:

2 uestis: uestimentis E H N O / maioris: maioribus E H N 3 nisi: <nisi> G / sacre: sacre E S U V Y / scripture: scripture A G H N scribture O scribture E S 4 preceptis: preceptis $\mathrm{H} \mathrm{S} \mathrm{Y} \mathrm{/} \mathrm{q.}$ que E H 5 fuerant: fuerunt $\mathrm{N} 6$ eis: eius $\mathrm{V} 7$ quem: quem A, pero $m$ borrada por deterioro que E N que OS 8 reliquid: relireliquit $G /$ reliquit $G^{c}$ reliquit $\mathrm{OU} /$ illa: illa $U$ / ille $\mathrm{U}^{\mathrm{c}} 9$ precepta: precepta H O S 10 que: que A G N U / Iudaicus: Iudaycus A G M N O U V Y 13 Isaac: Ysaac A E G H N S U V Y Isahac M O 14 quem: que O / benedicit: benedixit G be<ne>dicit U 15 de: om. G 15-16 psalmistam: salmistam G 16 dixit: dicit H / populum: populum $A$ / populus $A^{c} 17$ cognoui: gocnoui $G$ cognobi $H$ N U / seruiuit: seruibit H N S UY / mici: mihi M V V michi N m $\mathrm{m}^{\mathrm{i}}$ O 17-18 auditu: audita N 18 obaudiuit: obaudibit H N S VY / mihi: mici A E G H S $\mathrm{m}^{\mathrm{i}} \mathrm{O} 19$ ergo: om. E H N / presentem: presentem H S Y 20 que: que G M N 22 Deus: om. G / cum: quum $\mathrm{O} U$ que E/quum $\mathrm{E}^{\mathrm{c}} /$ per: om. M U V Y / profetas: prophetas E H M N U 22-23 predicaret: predicaret H M O V Y prediceret $\mathrm{S} 23$ gentilitati: gentilitatem $\mathrm{H}$ gentilitate E O 24 prerogandam: prerogandam $\mathrm{H}$ M S V Y prorogandam O / presenti: presenti $\mathrm{H}^{\mathrm{c}} \mathrm{M}$ O S U Y 25 per: pre $\mathrm{H}$ 24-25 eam in presenti per gratiam non $\mathrm{V}^{\mathrm{c}} 25$ que: que $\mathrm{A} U \mathrm{Y}$ quia $\mathrm{HNO}$ qui $\mathrm{E}$ que G/qua $G^{c} 26$ errore: sobre raspado en $\mathrm{H}$ errorem $\mathrm{N} /$ derelinquid: dereliquit $\mathrm{H}$ derelinquit $\mathrm{M}$ derelinquid N/dereliquid $\mathrm{N}^{\mathrm{c}}$ delinquid $\mathrm{O} 27$ quia: qui N/ hoc: $o m$. M 29 preuidit: preuidit $\mathrm{H} \mathrm{S} \mathrm{V} \mathrm{Y} \mathrm{preuidet} \mathrm{N/} \mathrm{unde:} \mathrm{te} \mathrm{add.} \mathrm{H}$ et add. $\mathrm{N} \mathrm{O} /$ idem: eidem $\mathrm{O} 30$ populi: populus $\mathrm{V} \mathrm{S}$ populus U/populi $\mathrm{U}^{\mathrm{c}} \quad$ / pupuli: <per>add. $\mathrm{N}^{\mathrm{c}} 31$ tenenti: tenendi $\mathrm{V} /$ benedictionem: benedictionem $\mathrm{A} /$ benedictione $\mathrm{A}^{\mathrm{c}}$ benedictione $\mathrm{O}$

\section{[fragmento 277r, b]}

$/{ }^{1}$ Ecce odor filii mei sicut odor agri pleni, $/ 2$ cui benedixit Domin $u$ s. Sicut en$\mathrm{im}$ in Eu- $/^{3}$ angelio ueritas dicit: Ager est hic $/^{4}$ mundus, et quia gentilis populus $\mathrm{ad} /{ }^{5}$ fidem perductus per electos suos in $/^{6}$ uniuerso mundo uirtutibus redolet, ${ }^{7}$ odor fili odor agri pleni.

Aliter namque $\beta^{8}$ olet flos uue, quia magna est $\rho^{9}$ uirtus et opinio predicatorum quid $/^{10}$ ebriant mentes audientium, aliter $/^{11}$ flos olibe, quia suabe est opus misericordie $/ /^{12}$ quod more olei refobet et lucet, $/^{13}$ aliter flos rose, quia mira est fraglan- $/^{15}$ tia que rutilat et redolet ex odore $/^{15}$ martirum, aliter flos lilii, quia can$1^{16} \mathrm{dida}$ carnis est de incorruptione uir- $/{ }^{17}$ ginitatis, aliter flos biole, quia $/ /^{18}$ magna est uirtus humilium, quia $/^{19}$ ex desiderio loca ultima tenentes, se ${ }^{20}$ per humilitate $m$ in altum licet non $/^{21}$ subleuet tamen celestis regio pur- $/^{22}$ puram in mentem seruat, aliter ${ }^{23}$ redolet spica, cum ad maturitatem $\rho^{24}$ perducitur, quia et bonorum operum $/{ }^{25}$ perfectio ad societatem eorum qui ius- $/^{26}$ titiam esuriunt preparatur. ${ }^{27}$ Quia ergo gentilis populus in electis suis $/^{28}$ ubique per mundum sparsus

Textos medievales

Hispania Sacra 55 (2003) 
est ${ }^{139}$, et ex eis $/^{29}$ uirtutibus quas agit omnipotens qui intel- $/{ }^{30}$ legunt odorem bone opinionis replet, $\beta^{31}$ dicatur recte: Ecce odor filii mei sicut

1 Ecce: Ecce S / odor: hodor O / filii: fili M N O S / mei: mi E G M O S / odor: hodor O 2 Dominus: Deus add. E H N / enim: om. O 2-3 in Euangelio ueritas: $t r .:$ ueritas in euangelio $\mathrm{E}$ O 2-3 Euangelio: Euangelio S 3 dicit: dixit G 4 populus: populis $G 5$ fidem: finem E / electos: electos S 6 mundo: mumdo G 7 odor: hodor O / fili: filii $A \mathrm{H} \quad$ fili $\mathrm{N} /$ filii $\mathrm{N}^{\mathrm{c}}$ / odor: hodor $\mathrm{O}$ / namque: nanque A 8 flos: flox N / uue: uue A

G O ube E M S ube H N U V Y 9 predicatorum: predicatorum H M O S V Y predic $<$ a $>$ torum $E$ / quid: qui N O 10 ebriant: ebriant $S$ / audientium: audentium V 11 olibe: olibe A/oliue $\mathrm{A}^{\mathrm{c}}$ olibe E G H M V Y oliue $\mathrm{O} /$ suabe: suabe $\mathrm{A} /$ suaue $\mathrm{A}^{\mathrm{c}}$ suaue $\mathrm{O}$

suabe S / misericordie: misericordie A E G H M 12 more: morte M / refobet: refobet $A$ /refouet $A^{c} \quad$ refouet $O \quad<$ refouet $>H^{c} 13$ rose: rose A E G H M N O U V Y 13-14 fraglantia: flagrantia $\mathrm{V} \quad 14$ que: que $\mathrm{A} \quad \mathrm{G} \mathrm{HNO} \mathrm{U} /$ odore: odorem V 15 martirum: martyrum $\mathrm{G}$ (con signo abreviativo superfluo sobre la $u$ ) $\mathrm{H} \mathrm{N}$ martyrum $\mathrm{M}^{\mathrm{c}} /$ lilii: lii $\mathrm{S}$ lili U 16 candida: add. castitas $\mathrm{N}^{\mathrm{c}} 16-17$ uirginitatis: ueritatis V/uirginitatis $\mathrm{V}^{\mathrm{c}} /$ biole: biole A/uiole $A^{c}$ biole G U V Y uiole E H N O uiole S 18 uirtus: uitus M / quia: qui E H N O 19 desiderio: desidesiderio G/desiderio $G^{\mathrm{c}} 19-20$ se per: semper E H N O V 20 humilitatem: humilitate $\mathrm{EN}$ umilitate $\mathrm{H} /$ humilitatem: seruat $a d d$. G 21 subleuet: subleuet $\mathrm{A} /$ subleuent $\mathrm{A}^{\mathrm{c}}$

sublebet E H S V sublbet (sic) U subleuent $\mathrm{N}^{\mathrm{c}} /$ celestis: celestis A E G <stis regio> U / regio: regi H O U regni E N 21-22 purpuram: purpura $V$ mentem: mente $O 22$ seruat: seruat A N/seruant $A^{c} N^{c}$ seruant $O$ serbat $S$ U V 23 cum: quum E H M O S U Y quam V 26 esuriunt: esuriunt $\mathrm{S} /$ preparatur: preparatur $\mathrm{O} S 27$ electis: electis $\mathrm{S} 28$ mundum: ad add. $\mathrm{N}$ $<\mathrm{ad}>$ add. $\mathrm{G}^{\mathrm{c}}$ / et: om. S U <et> V 29 agit: agyt H / omnipotens: omnes E N O / omnipotens: omnes add. H 29-30 intellegunt: intellegunt $\mathrm{V} /$ intelligunt $\mathrm{V}^{\mathrm{c}} 30$ odorem: odorem $\mathrm{A}$ N/odore $\mathrm{A}^{\mathrm{c}} \mathrm{N}^{\mathrm{c}}$ odore $\mathrm{H}$ hodore: $\mathrm{O} /$ bone: bone $\mathrm{S} 31$ odor: hodor $\mathrm{O} /$ filii: fili E M N O S V / mei: mi E G O

\section{[fragmento 277v, a]}

$/^{1}$ odor agri pleni. Sed quia [easd]em $/^{2}$ uirtutes ex [s]emedips[a] ${ }^{140}$ non ha[bet], $\beta$ adiungat: Cui benedixit Domin[us].

$/^{4}$ Et quoniam isdem electorum populus per $/ 5$ quosdam etiam in contempla$\mathrm{ti}-/^{6}$ one surgit, per quosdam uero in $/ 7$ actiue uite solummodo opera $/{ }^{8}$ pinguescit, recte illic additvr: $/^{9}$ det tibi Domin $u$ s de rore celi et pingve- $/^{10}$ dine terre. Ros enim desuper et sub- $/{ }^{11}$ tiliter cadit. Et [qu]otiens de ro- $/^{12}$ re celi accipimus, totiens per in- $/^{13}$ effusionem contemplationis in $/{ }^{14}$ time de supernis aliquid te-

139 Corrección sobre raspado.

140 Los rasgos conservados nos conducen más a una $a$ final que a una $o$. Asimismo, el mínimo espacio tras la $x$ podría indicar que no hubo inicialmente una $s$ y se escribió exemedipsa (lectura que hallamos en U). 
nui- $/{ }^{15}$ ter uidemus. Quum uero bona opera $/{ }^{16}$ etiam per corpus agimus, et e[te]rre (?) pin- $/^{17}$ guedine ditamur.

Quid est au[tem] $/ /^{18}$ quod Esau ad patrem [tard]ius $/{ }^{19}$ redit, nisi quod Iu$\mathrm{da}[\mathrm{y}]$ cus [populus] $/^{20}$ ad placendum Domino sero reuertitvr? $/^{21}$ Cui et hoc in benedictione dicitvr: $/^{22}$ Tempus [que] erit cum soluatur iugu[m] $/ /^{23}$ de collo tuo. Quia a seruitute $/^{24}$ peccati Iuda[i]cus populus in fine $/^{25}$ liberabitur, sicut scribtum est: ${ }^{26}$ Donec plenitudo gentium introiret, ${ }^{27}$ et sic omnis Srahel saluus fieret.

${ }^{28}$ Quem non paruulorum ipsa euan- $/{ }^{29}$ gelica storia in miraculi ope$\beta^{30}$ ratione reficiat, quod idrias $\beta^{\beta 1}$ uacuas [Dominus] aqua impleri precepit

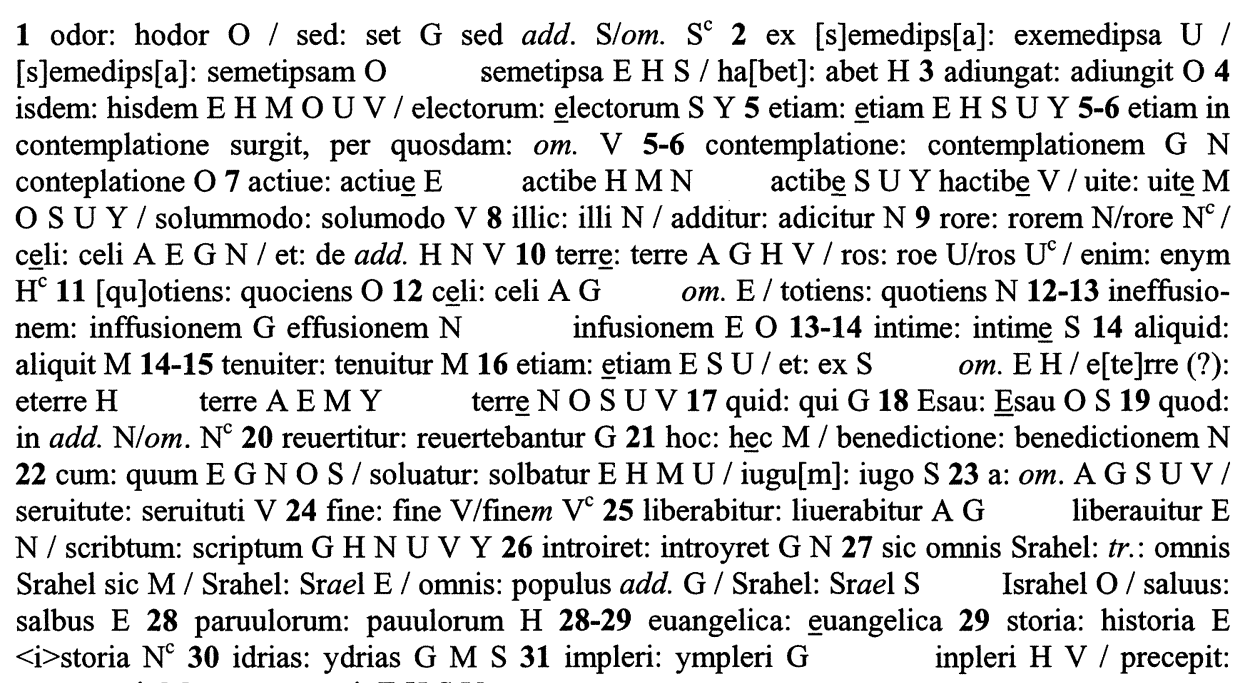
$\mathrm{p}<\mathrm{r}>$ ecepit $\mathrm{M}$ precepit E H S V

\section{[fragmento 277v, b]}

$/^{1}$ [eandemque aquam statim] in uino $/^{2} \mathrm{u}$ [ertit? Sed cu]m euigilanti- $/^{\beta}$ or[e]s in[g]enio audi[unt], et sa- $/^{4}$ cra storia credendo ueneran $-/^{5}$ tur, quid interius innuat re- $/^{6}$ quirunt. Qui enim mutare $/^{7}$ aquam in uino potuit, etiam $/^{8}$ uacuas idrias ualuit uino $/^{9}$ [stat]im replere. Sed impleri $/^{10}$ idrias aqua iubet, quia ipsivs $/^{11}$ [et] sacre lectionis storia corda $/^{12}$ nostra replenda sunt. Et a[q]uam $/^{13}$ nobis in uino uertit, [q]uando ipsa $/{ }^{14}$ storia per allegorie misterium $/{ }^{75}$ in spiritalem nobis intellegentiam $/{ }^{16}$ conmutatur. Rota ergo qvasi $/{ }^{17}$ per terram traitur, quia paruu- $/{ }^{18}$ lis humili sermone concordat, $/{ }^{19}$ et tamen magnis spiritalia in-

Textos medievales

Hispania Sacra 55 (2003) 
fun- $/^{20}$ dens, quasi circulum in altum $/^{21}$ leuat, e $[\mathrm{t}]$ inde rursum erigitur, $/^{22}$ unde terram tangere paulo ante ${ }^{23}$ uide [ba]tur.

Quia uero undique edi- $/ 24$ ficat, quasi per circulum rota cvrrit. ${ }^{25}$ Unde et in lege scriptum est: Facies $/^{26}$ candelabrum ductilem de auro $/^{27}$ mundissimo, astile eius et cala- $/{ }^{28}$ mos, sciffos et sferulas ac lilia $/{ }^{29}$ ex ipso proc[i]dentia. Quis in can- ${ }^{\beta 0}$ delabro nisi Redemto $<\mathrm{r}>$ humani $\beta^{\beta 1}$ [ge]neris designatur? Qui in natura

\footnotetext{
2 uertit: conuertit en $\mathrm{N}^{\mathrm{c}} 3$ euigilantiores: in add. $\mathrm{M}<$ in $>\mathrm{E}^{\mathrm{c}} /$ in[g]enio: inienio $\mathrm{S} U \mathrm{~V}$ Yieiunio $\mathrm{E}$ $\mathrm{H} \mathrm{M} \mathrm{O} \mathrm{/} \mathrm{et:} \mathrm{ea} \mathrm{V} \mathrm{3-4} \mathrm{sacra:} \mathrm{sacram} \mathrm{N} \mathrm{sacra} \mathrm{A/sacram} A^{c} \quad 4$ storia: historia $E$ storiam $\mathrm{N}<\mathrm{i}>$ storiam $\mathrm{A}^{\mathrm{c}} 5$ innuat: in $<\mathrm{si}>$ nuat $\mathrm{G}$ insinuat $\mathrm{N} 6$ qui: quid $\mathrm{G} 7$ aquam: aqua $U$ a add. M / etiam: etiam E S U V Y 8 ualuit: baluit $\mathrm{H}$ uoluit $\mathrm{N} 10$ idrias: ydrias H U V Y / quia: in add. G 11 sacre: sacre $\mathrm{S} /$ lectionis: lectiones A E M / storia: $<\mathrm{i}>$ storia $\mathrm{N}^{\mathrm{c}}$ historia E 12 replenda: repleta $G$ repleda $\mathrm{O} 14$ storia: $<\mathrm{i}>$ storia $\mathrm{N}^{\mathrm{c}}$ historia $\mathrm{E} /$ allegorie: allegorie G H M N O allogorie N/ misterium: mysterium $\mathrm{E} \mathrm{M}^{\mathrm{c}} 15$ intellegentiam: intellegentiam N/intelligentiam $\mathrm{N}^{c}$ / intellegentiam: intellentiam $\mathrm{H} 16$ conmutatur: comutatur $\mathrm{G}$ commutatur $\mathrm{H} 17$ traitur: tra $<\mathrm{h}>$ itur $\mathrm{A}^{\mathrm{c}}$ traytur $\mathrm{M} U \mathrm{U}$ 17-18 paruulis: paruulus $\mathrm{E} 21$ leuat: lebat $\mathrm{E}$ H M N S V Y 23-24 edificat: hedificat $H$ edificat S U 24 per: om. M 25 scriptum: scribtum E O S 26 ductilem: ductile O 27 mundissimo: mundissim G / astile: adstile G 27-28 calamos: calamus (calam ${ }^{s}$ ) $\mathrm{N}$ calam ${ }^{\mathrm{s}}$ os (calamusos) H 28 sciffos: sciffos A/scifos $\mathrm{A}^{\mathrm{c}} \quad$ scifos E G H M N O S U V Y / ac: hac A G U V Y / lilia: libia $M^{c} 29$ proc[i]dentia: producentia N / quis: quid O 30 redemto $<\mathrm{r}>$ : redem $<\mathrm{p}>$ tor $\mathrm{A}$ redemptor $\mathrm{OS} \mathrm{U}$
} 


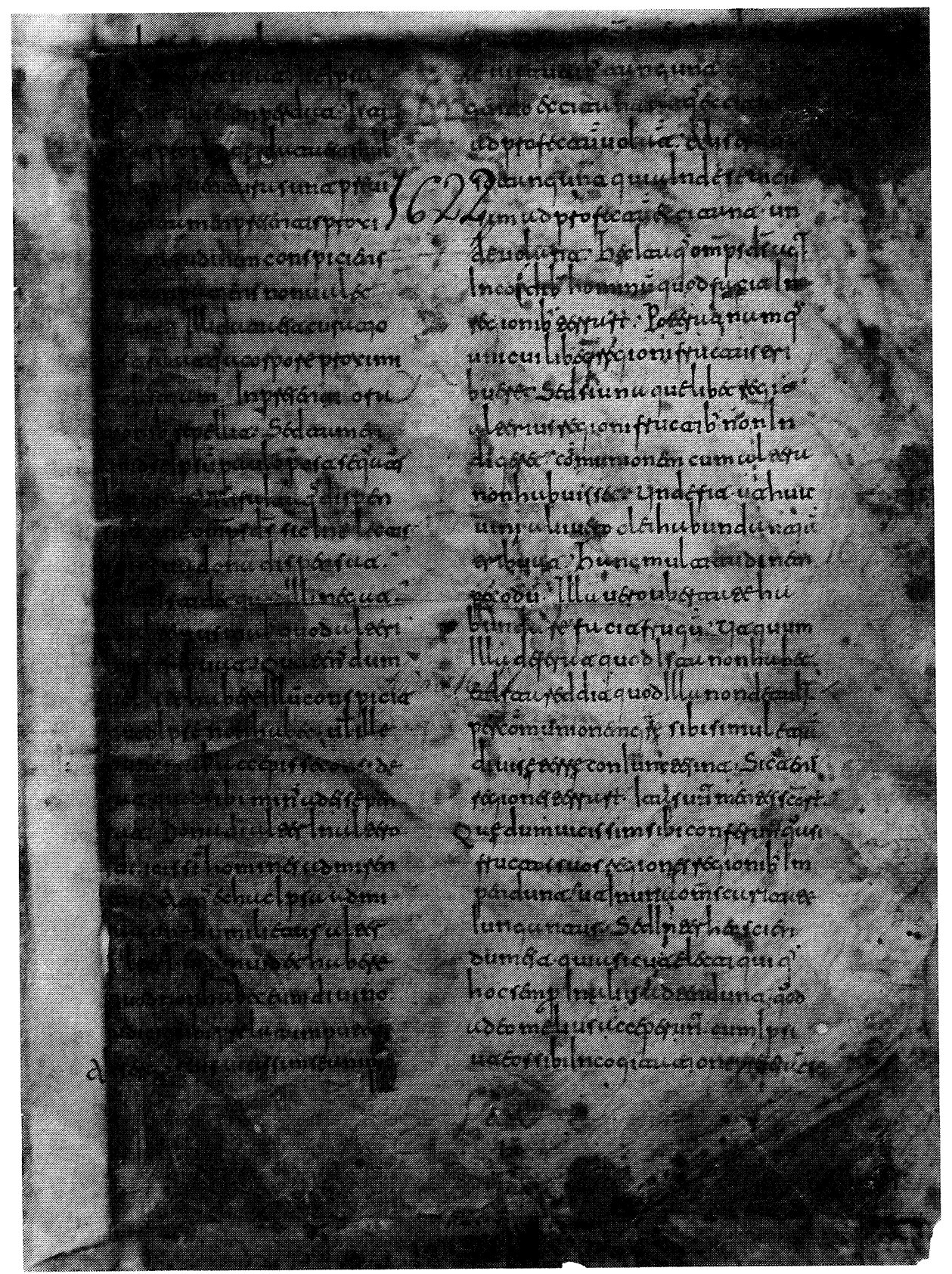

Lámina 1. Zamora, A.H.P., fragmento 276, recto del folio.

Textos medievales

Hispania Sacra 55 (2003) 


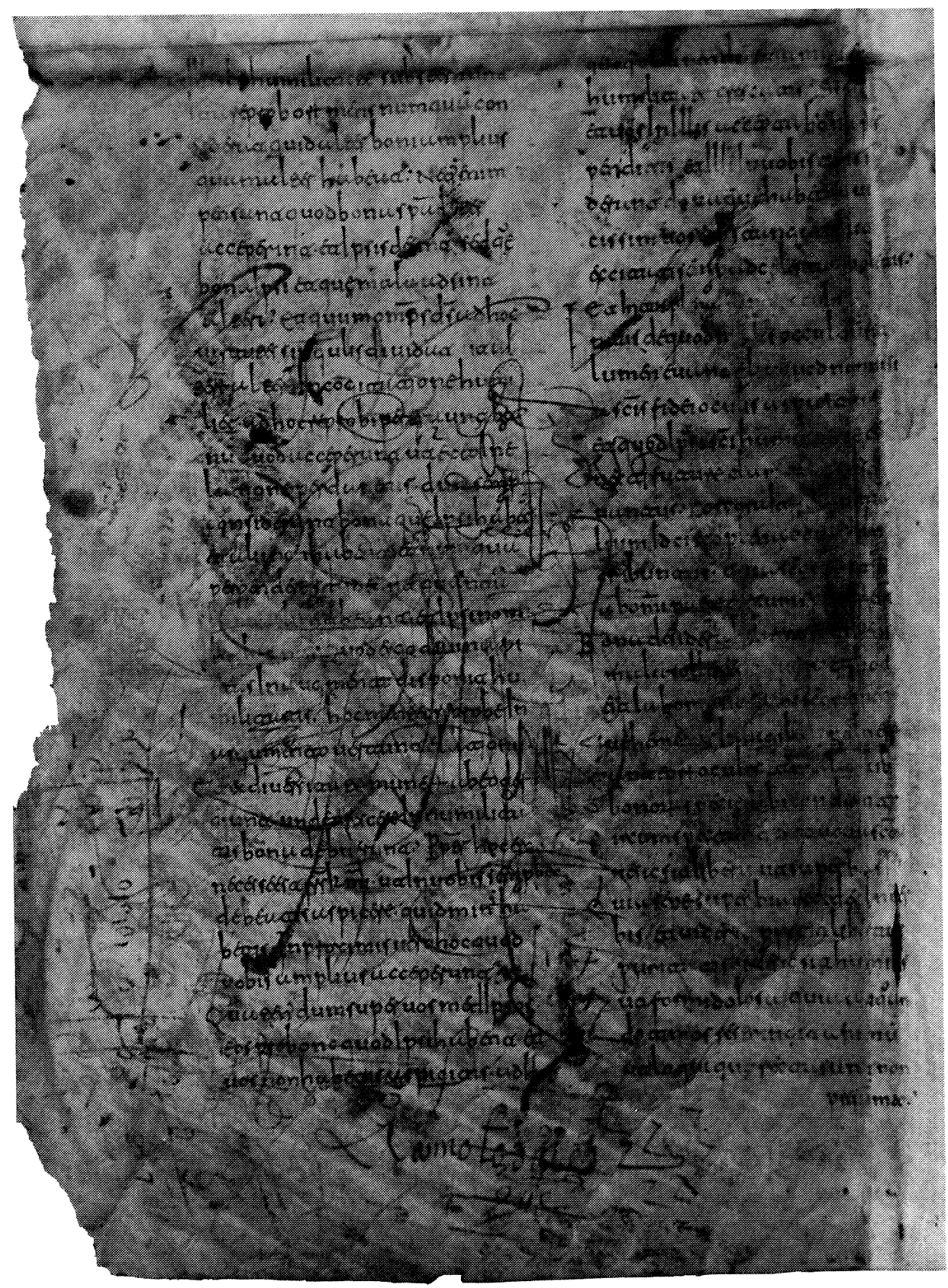

Lámina 2. Zamora, A.H.P., fragmento 276, vuelto del folio.

Textos medievales Hispania Sacra 55 (2003) 


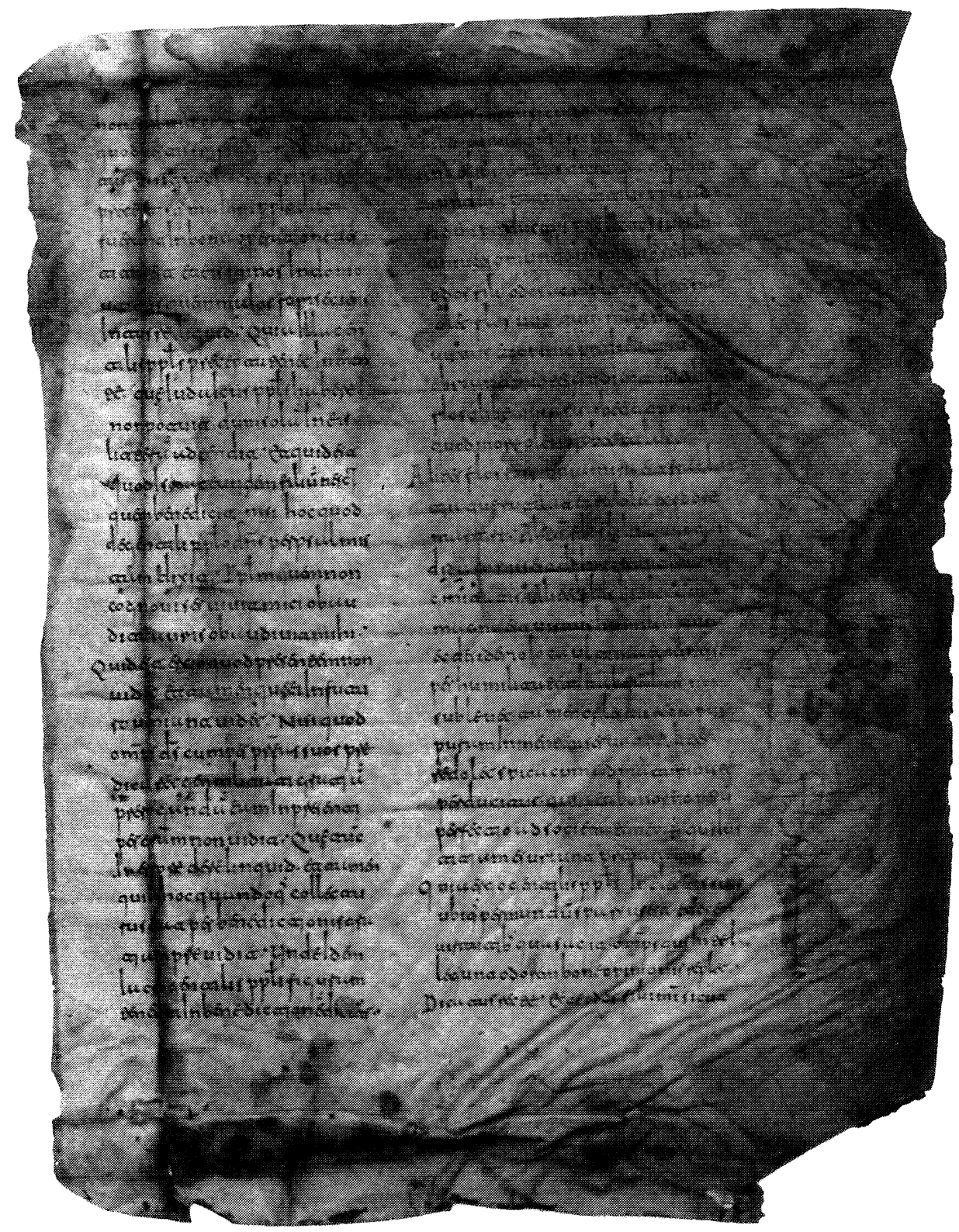

Lámina 3. Zamora, A.H.P., fragmento 277, recto del folio.

Textos medievales

Hispania Sacra 55 (2003) 




Lámina 4. Zamora, A.H.P., fragmento 277, vuelto del folio.

Textos medievales

Hispania Sacra 55 (2003) 